\title{
Changes in Central Sodium and not Osmolarity or Lactate Induce Panic-Like Responses in a Model of Panic Disorder
}

\author{
Andre I Molosh',4, Philip L Johnson ${ }^{1,4}$, Stephanie D Fitz', Joseph A DiMicco², James P Herman ${ }^{3}$ and \\ Anantha Shekhar*,1,2
}

'Department of Psychiatry, Indiana University School of Medicine, Indianapolis, IN, USA; ' Department of Pharmacology and Toxicology, Indiana University School of Medicine, Indianapolis, IN, USA; ${ }^{3}$ Department of Psychiatry, University of Cincinnati, Genome Research Institute, Cincinnati, $\mathrm{OH}$, USA

\begin{abstract}
Panic disorder is a severe anxiety disorder characterized by recurrent panic attacks that can be consistently provoked with intravenous (i.v.) infusions of hypertonic ( $0.5 \mathrm{M})$ sodium lactate ( $\mathrm{NaLac}$ ), yet the mechanism/CNS site by which this stimulus triggers panic attacks is unclear. Chronic inhibition of GABAergic synthesis in the dorsomedial hypothalamus/perifornical region (DMH/PeF) of rats induces a vulnerability to panic-like responses after i.v. infusion of $0.5 \mathrm{M} \mathrm{NaLac}$, providing an animal model of panic disorder. Using this panic model, we previously showed that inhibiting the anterior third ventricle region ( $\mathrm{A} 3 \mathrm{~V}$; containing the organum vasculosum lamina terminalis, the median preoptic nucleus, and anteroventral periventricular nucleus) attenuates cardiorespiratory and behavioral responses elicited by i.v. infusions of $\mathrm{NaLac}$. In this study, we show that i.v. infusions of $0.5 \mathrm{M} \mathrm{NaLac}$ or sodium chloride, but not iso-osmolar D-mannitol, increased 'anxiety' (decreased social interaction) behaviors, heart rate, and blood pressure responses. Using whole-cell patch-clamp preparations, we also show that bath applications of NaLac (positive control), but not lactic acid (lactate stimulus) or D-mannitol (osmolar stimulus), increases the firing rates of neurons in the $\mathrm{A} 3 \mathrm{~V} r$, which are retrogradely labeled from the DMH/PeF and which are most likely glutamatergic based on a separate study using retrograde tracing from the DMH/PeF in combination with in situ hybridization for vesicular glutamate transporter 2 . These data show that hypertonic sodium, but not hyper-osmolarity or changes in lactate, is the key stimulus that provokes panic attacks in panic disorder, and is consistent with human studies.

Neuropsychopharmacology (20 I0) 35, I333-1347; doi:I0.1038/npp.20 I0.2; published online 3 February 2010
\end{abstract}

Keywords: anxiety; hypothalamus; panic; sodium lactate; DMH; OVLT

\section{INTRODUCTION}

Panic disorder is a condition characterized by recurrent, unprovoked panic attacks consisting of extreme anxiety and marked changes in cardio-respiration activity (eg, rapid heartbeat, perspiration, dizziness, dyspnea, trembling, psychological experience of uncontrollable fear, hyperventilation, and so on) resulting in significant morbidity (DSMIV, 1994). The disorder presents early in life, tends to have a chronic recurrent course if untreated, and is often complicated by other psychiatric illnesses, especially agoraphobia, major depression, and substance use disorders (Magee et al, 1996). Although patients report that most panic attacks are unprovoked, one of the most consistent abnormalities in panic disorder is a vulnerability to showing panic attacks to normally innocuous inter-

*Correspondence: Dr A Shekhar, Department of Psychiatry, Indiana University School of Medicine, I I I I West I Oth Street, Indianapolis, IN 46202, USA, Tel: + I 317278 9047, Fax: + I 3172789739 ,

E-mail: ashekhar@iupui.edu

${ }^{4}$ These two authors contributed equally to this work.

Received 12 August 2009; revised 24 November 2009; accepted 21

December 2009 oceptive stimuli such as hypertonic $(0.5 \mathrm{M})$ sodium lactate (NaLac) (Liebowitz et al, 1984, 1986a), with greater than $70 \%$ of panic disorder patients, and very few healthy controls, showing this sensitivity (see the review by Shekhar et al, 2003). Furthermore, the range of symptoms reported by panic disorder patients from recalled panic attacks compared with NaLac-provoked panic attacks are very similar (Goetz et al, 1994). Thus, the initial pathology in these patients appears to be an alteration somewhere in the central neural pathways regulating normal panic responses, thus rendering the patients susceptible to unprovoked panic symptoms when exposed to ordinarily mild interoceptive stressors (Vickers and McNally, 2005). As mild changes in interoceptive sensory stimuli are largely unnoticed, panic attacks can seem unprovoked or 'spontaneous'.

Studies conducted on panic disorder patients suggest that increased sodium, not lactate or osmotic stress, may be the critical component provoking panic attacks. For instance, intravenous (i.v.) infusions of hypertonic $(0.5 \mathrm{M}) \mathrm{NaLac}$, sodium chloride $(\mathrm{NaCl})$ (Peskind et al, 1998), or sodium bicarbonate (Gorman et al, 1989) provoke equivalent panicassociated responses in panic disorder patients. Furthermore, panic disorder patients are significantly more likely 
to have a panic attack after i.v. infusions of hypertonic $\mathrm{NaCl}$ rather than lactate dissolved in dextrose (George et al, 1995). Therefore, we hypothesized that sodium is the critical panic-provoking component of an NaLac challenge. To test the above hypotheses, we measured the effects of three sensory components of the NaLac challenge (ie, changes in sodium, lactate, or osmotic stress) to observe which of them is critical for the provocation of panic-like responses. To do this, we challenged panic-prone rats with i.v. infusions of hypertonic $(0.5 \mathrm{M})$ D-mannitol for an osmotic stressor, $\mathrm{NaCl}$ as a sodium stressor, or NaLac as a positive control.

The sensory mechanism and site by which this interoceptive challenge triggers panic attacks in panic disorder patients is also unknown. Using the same animal model of panic disorder, we have previously shown that inhibiting the anterior third ventricle region (A3Vr: comprising the vascularized organum vasculosum lamina terminalis (OVLT), a circumventricular organ (CVO), that is, highly vascularized regions that lack a blood-brain barrier and adjacent median preoptic nucleus (MnPO) and anteroventral periventricular nucleus (AVP)) attenuates panic-like cardiorespiratory and 'anxiety'-associated responses as a result of i.v. infusions of $0.5 \mathrm{M}$ hypertonic NaLac in panicprone rats (Shekhar and Keim, 1997). Therefore, we further hypothesize that NaLac challenge is most likely 'sensed' at 'osmo- and/or sodium-sensitive' CVOs, which relay (Hochstenbach and Ciriello, 1996) changes in plasma parameters to 'panic'-generating CNS sites such as the dorsomedial hypothalamus (DMH) (Shekhar and DiMicco, 1987; Shekhar et al, 1990). To test this hypothesis, we used whole-cell patch-clamp studies to determine the effects of bath application of hypertonic $(0.5 \mathrm{M}) \mathrm{NaLac}$, lactic acid, or D-mannitol on neurons in the $\mathrm{A} 3 \mathrm{Vr}$ that were retrogradely labeled from the DMH.

\section{MATERIALS AND METHODS}

\section{Animals and Housing Conditions}

All experiments were conducted on adult male SpragueDawley rats (300-350 $\mathrm{g}$ for in vivo studies and 190-200 $\mathrm{g}$ for in vitro studies), which were purchased from Harlan Laboratories and were housed individually in plastic cages under standard environmental conditions $\left(22^{\circ} \mathrm{C} ; 12 / 12\right.$ light-dark cycle; lights on at 0700 hours) for 7-10 days before the surgical manipulations. Food and water were provided ad libitum. Animal care procedures were conducted in accordance with the NIH Guidelines for the Care and Use of Laboratory Animals (NIH Publication no. 80-23) that were revised in 1996, and the guidelines of the IUPUI Institutional Animal Care and Use Committee.

\section{Experiment 1 - In Vivo Studies}

Surgical procedures and osmotic minipump infusions. Before surgery, rats were anesthetized by placing them in a closed plexiglass box, which was connected to an isoflurane system (MGX Research Machine; Vetamic, Rossville, IN) and then with a nose cone connected to the same system during the surgery. All rats were fitted with femoral arterial catheters for measurement of mean arterial blood pressure (MAP) and heart rate (HR) and with venous catheters for i.v. infusions, as previously described (Shekhar et al, 1993).

Cardiovascular responses were measured by an arterial line connected to a telemetrical probe, which contained a pressure transducer (Cat. no. C50-PXT, Data Science International (DSI)). Windows-based DSI DATAQUEST software was used to monitor and record MAP and HR as well as general activity. For the duration of experiment 1, MAP, HR, and activity were recorded continuously in freely moving conscious rats and are expressed as a time course. The data reported are changes in HR and MAP from the average of the baseline $(t-5$ to $t-1)$ from each treatment group.

After 3 days of recovery, animals were tested for baseline cardiovascular and respiratory responses to lactate (see below). Each rat was then implanted with a 28-gauge cannula attached to a T-shaped Alzet osmotic minipump (DURECT Corporation, Cat. no. 3260PG, 26 gauge) as described earlier (Shekhar et al, 1996). Briefly, cannulae were directed at cardioexcitatory regions of the DMH (see Johnson and Shekhar, 2006) based on the following coordinates from a Standard Stereotaxic Atlas of the Rat Brain ((Pellegrino et al, 1979), from bregma: $1.2 \mathrm{~mm}$ posterior, $+2.1 \mathrm{~mm}$ lateral, $+9.1 \mathrm{~mm}$ ventral and adjusted for approaching at a $+10^{\circ}$ angle toward the midline with the stereotaxic incisor bar elevated $5 \mathrm{~mm}$ above the interaural line). A T-shaped pump cannula with a side arm attached to a small Tygon tube was used for pump implantations. The minipump was then filled with L-allylglycine (L-AG: an inhibitor of GABA synthesis, Sigma, St Louis, MO). Allylglycine is the precursor to 2-keto-4pentanoic acid, which is a nonspecific inhibitor of isoforms of glutamic acid decarboxylase (ie, GAD65 and GAD67). To inhibit the synthesis of GABA, allylglycine must first be transformed into its active form, 2-keto-4-pentenoic acid, by amino acid oxidase enzymes (Orlowski et al, 1977; Reingold and Orlowski, 1978, 1979) that are expressed throughout the brain (Goldstein, 1966; Neims et al, 1966). Consistent with these facts is that in vivo systemic administration of L-AG into rats reduces levels of GABA throughout the brain (Horton et al, 1978), but in vitro L-AG does not affect (Fernandez-Pascual et al, 2004; Reingold et al, 1979) GAD activity. The concentration of the $\mathrm{L}-\mathrm{AG}$ solutions was such that $3.5 \mathrm{nmol} / 0.5 \mu \mathrm{l}$ per hour of the drug was infused into the $\mathrm{DMH}$ region over a 5-day period before i.v. infusions of $\mathrm{NaLac}, \mathrm{NaCl}$, or D-mannitol. Previous studies have determined that the dose of L-AG used here reduces local GABA concentrations by approximately $60 \%$ after unilateral infusions based on microdialysis study (Abshire et al, 1988), and enzyme assays (Shekhar et al, 1987, 1996, 1997, 2006) and supported by immunohistochemistry (Johnson and Shekhar, 2006) and increases anxiety-like behavior (ie, as measured by the social interaction (SI) test and elevated plus maze (EPM)) without increasing cardiorespiratory responses (Shekhar et al, 1987, 1996, 1997, 2006). We have also conducted multiple immunocytochemistry studies of the infusion sites in the DMH and have shown that there is minimal mechanical damage from these prolonged infusions (Johnson and Shekhar, 2006).

Description of the i.v. infusions. Five days after stereotaxic surgery, rats were randomly assigned to three groups $(n=6$ 
each): (1) $0.5 \mathrm{M}$ D-mannitol, (2) $0.5 \mathrm{M} \mathrm{NaCl}$, and (3) $0.5 \mathrm{M}$ NaLac. Rats were given their assigned i.v. infusion and HR, MAP, and general activity were recorded continuously for $5 \mathrm{~min}$ before infusion (baseline) until $20 \mathrm{~min}$ after the onset of the i.v. infusion. The i.v. infusion procedure has been described earlier (Shekhar et al, 1996). Briefly, freely moving rats in home cages were given i.v. infusions $(10 \mathrm{ml} / \mathrm{kg}$ over $15 \mathrm{~min}$ ), similar to clinical NaLac infusions (Liebowitz et al, 1986b). Cardiovascular responses that are reported are the changes from the minimum baseline value for HR (in beats/ $\mathrm{min}$ ) and MAP (in $\mathrm{mm} \mathrm{Hg}$ ) relative to the maximum $\mathrm{HR}$ and MAP during the post-infusion period for each animal.

SI test. The SI test is a fully validated test of experimental anxiety-like behavior in rats (File, 1980; File and Seth, 2003), and the procedure as used in our laboratory has been described earlier (Shekhar and Katner, 1995). The apparatus itself consists of a solid wooden box with an open roof approximately $0.9-\mathrm{m}$ long $\times 0.9-\mathrm{m}$ wide with walls $0.3-\mathrm{m}$ high. A video camera is fixed above the box, and all behavioral tests are videotaped. The 'experimental' rat and an unfamiliar 'partner' rat are both placed individually in the center of the box and allowed to habituate to the environment for a 5 -min period $24 \mathrm{~h}$ before each SI test. During the SI test, the two rats are placed together in the center of the box, and the total duration (second) of nonaggressive physical contact (grooming, sniffing, crawling over and under, and so on) initiated by the 'experimental' rat is quantified over a 5-min duration. A baseline SI test was performed $72+$ hours after i.v. catheterization, but before osmotic minipump implantation. Another SI test was performed 5 days after infusions of L-AG into the DMH region through osmotic minipumps and immediately after i.v. infusions. Videotaped sessions were scored at a later time by SDF, who was blind to any drug treatment.

Minipump cannula-placement verification. On completion of experiment 1 , rats were anesthetized as previously described, decapitated, brains removed, frozen in isopentane previously cooled with dry ice, then sectioned coronally at $30-\mu \mathrm{m}$ thickness on a freezing cryostat, mounted on slides, dried overnight, hydrated, and stained with $1 \%$ methyl green solution in $\mathrm{H}_{2} \mathrm{O}$ (Cat. no. 198080, Sigma). Minipump cannula tip placement was verified at $\times 400$ magnification using a Leica DMLB trinocular microscope (Fisher Scientific), by an investigator (PLJ) who was blind to the experimental treatment of each rat.

Data generation and statistical analyses. Each dependent variable for in vivo analyses (ie, SI duration, HR, MAP, general activity) was analyzed using a one-way ANOVA with repeated measures with i.v. infusion as the main factor and time as repeated measures. In the presence of significant main effects or main effect $\times$ time interactions, appropriate post hoc tests were conducted to determine within- and between-subjects effects. Specifically, ANOVA with Tukey's (honestly significantly different) HSD for between-subjects analyses, and Dunnett's post hoc analysis were used to compare the data for within-subjects time effects. All statistical analyses were carried out using SYSTAT 5.02 for Windows (SYSTAT), and all graphs were generated using SigmaPlot 2001 for Windows (SPSS).

\section{Experiment 2-In Vitro Electrophysiology}

Labeling of neurons in the A3Vr that project to the DMH. Rats were anesthetized with a mixture of ketamine and xylazine $(80 \mathrm{mg} / \mathrm{kg}$ ketamine; $11.5 \mathrm{mg} / \mathrm{kg}$ xylazine i.p., supplemented as required) and then placed in a stereotaxic frame (ASI Instruments, Warren, MI). The DMH was targeted at coordinates from bregma: posterior $-1.5 \mathrm{~mm}$, lateral +2.0 , ventral $-8.2 \mathrm{~mm}$. The incisor bar was situated $5 \mathrm{~mm}$ above horizontal and the arms were canted away from midline at $10^{\circ} \mathrm{C}$ from vertical. Glass pipettes $(1.0 \mathrm{~mm} \mathrm{OD}$, $0.25 \mathrm{~mm}$ ID, A-M Systems, Carlsboro, WA) were pulled to a long thin shaft (Model 700c, David Kopf Instruments, Tujunga Canyon, CA) and subsequently ground to a beveled tip between $20-40 \mu \mathrm{m}$ ID Pipettes were filled with $1 \%$ red (580/605) carboxylate-modified fluorescent microbeads $(0.04 \mu \mathrm{m})$ (Molecular Probes, Eugene, OR) dissolved in physiological solution. The fluorescent microbeads were injected into the DMH using positive pressure (Harvard Apparatus, Holliston, MA), and the animals were allowed to recover from surgery for 7-10 days before being used for electrophysiological studies.

Slice preparation. On the day of an experiment, rats were deeply anesthetized with Nembutal $(50 \mathrm{mg} / \mathrm{kg})$ and immediately decapitated. The brain was then removed from the skull and placed in a cold $\left(0-1{ }^{\circ} \mathrm{C}\right)$ extracellular Kreb's solution (in mM: $126 \mathrm{NaCl}, 2.5 \mathrm{KCl}, 1.2 \mathrm{NaH}_{2} \mathrm{PO}_{4}, 1.2$ $\mathrm{MgCl}_{2}, 2.4 \mathrm{CaCl}_{2}, 25 \mathrm{NaHCO}_{3}, 11$ D-glucose) aerated with $95 \% \mathrm{O}_{2}, 5 \% \mathrm{CO}_{2}$. A block of brain tissue containing the posterior region of the hypothalamus (ie, containing DMH) was taken to confirm injection sites of the retrograde tracer, and anterior regions of the hypothalamus (ie, containing OVLT and MnPO) were taken for electrophysiology. The anterior hypothalamus was quickly dissected from the brain and affixed with cyanoacrylonate glue to the cutting stage of a vibrating microtome (Leica VT1000S, Leica Microsystems, Deerfield, IL). Two to three coronal sections (250- $\mu \mathrm{m}$ thick) containing the OVLT and MnPO were cut from the block of the tissue and immediately transferred to a bath of aerated Kreb's solution maintained at $32 \pm 2{ }^{\circ} \mathrm{C}$, in which they were allowed to equilibrate for at least $1 \mathrm{~h}$ before recording started.

Whole-cell recording technique. Patch pipettes were pulled from Schott no. 8250 glass (OD $1.5 \mathrm{~mm} / \mathrm{ID} 0.75 \mathrm{~mm}$; World Precision Instruments, Sarasota, FL) on a Flaming-Brown puller (Model P-87, Sutter Instrument, Novato, CA). The tips of the pipettes were fire-polished to final shape (MF-830 Microforge, Narishige International USA, East Meadow, $\mathrm{NY}$ ) and had resistances between 4 and $6 \mathrm{M} \Omega$. For both current-clamp and voltage-clamp recording, the pipette solution contained, in $\mathrm{mM}$ : $128 \mathrm{~K}$-gluconate, $10 \mathrm{KCl}, 10$ $\mathrm{NaCl}, 0.3 \mathrm{CaCl}_{2}, 1 \mathrm{MgCl}_{2}, 10 \mathrm{~N}$-2-hydroxyethylpiperazine$N^{\prime}$-2-ethanesulfonic acid (HEPES), 1 ethylene glycol-bis ( $\beta$-aminoethyl ether)- $N, N, N^{\prime}, N^{\prime}$-tetraacetic acid (EGTA), $2 \mathrm{mM}$ ATP, and $0.25 \mathrm{mM}$ GTP. Osmolality of the pipette solution was adjusted when needed to a final level of $285-295 \mathrm{mmol} / \mathrm{kg}$ by addition of sorbitol. The extracellular Kreb's solution was maintained at $32 \pm 2{ }^{\circ} \mathrm{C}$, aerated with $95 \% \mathrm{O}_{2}, 5 \% \mathrm{CO}_{2}$ mixture, and had a final osmolality of 290-300 mmol/kg. NaLac, D-mannitol, and lactic acid 
(Sigma) were added to the Kreb's solution in concentrations of 20,40 , and $20 \mathrm{mM}$, respectively. In each case, the final osmolality of this modified Kreb's solution was 340$350 \mathrm{mmol} / \mathrm{kg}$. The $\mathrm{pH}$ was adjusted to 7.4 using Tris base (Sigma).

Electrophysiological signals were recorded with an Axoclamp 2B amplifier and HS-2A headstage (Molecular Devices Corp., Sunnyvale, CA) and simultaneously amplified and low pass filtered $(5 \mathrm{kHz})$ with a two channel preamplifier (LPF 202A, Warner Instrument, Hamden, CT). Amplified signals were digitized (Digidata 1322A, Molecular Devices Corp.) and recorded to disk on a PC running pClamp 9.2 data acquisition software (Molecular Devices Corp.).

Optics and visualization of brain slices. Cell-attached patch-clamp configuration was obtained under visual control using a Nikon Eclipse E600FN microscope (Nikon, Japan) equipped with infrared illumination and differential interference contrast optics (IR-DIC). Images were captured using a CCD camera C2400-77 enhanced for contrast and brightness (Hamamatsu, Bridgewater, NJ) and showed on a video monitor. Individual neurons were first visualized in DIC using a $40 \times$ water immersion objective, and then cells containing fluorescent microbeads were visualized using epifluorescence illumination $(530-560 \mathrm{~nm}$ excitation, $565 \mathrm{~nm}$ dichroic 573-648 bandpass emission) with variable intensity mercury lamp system. Fluorescence illumination times were minimized to avoid possible phototoxicity from the excitation of the fluorescent microbeads. Still images of labeled neurons were recorded and showed over real-time IR-DIC images to positively identify labeled neurons by a second digital Spot RT Slider camera (Diagnostic Instruments, Sterling Heights, MI). Standard techniques were used to generate the whole-cell recording configuration (Bailey et al, 2003).

Analysis of spontaneous synaptic potentials. To examine the effects of NaLac application on spontaneous synaptic activity, $\mathrm{A} 3 \mathrm{Vr}$ neurons were held at a holding potential of $-70 \mathrm{mV}$. As reported previously, no GABAergic or glycinergic transmission is observed at this holding potential (Iyadomi et al, 2000; Lao et al, 2001; Yoshimura and Nishi, 1995).

Spontaneous excitatory postsynaptic potentials (sEPSPs) were detected using the MiniAnalysis 6.0 software (Synaptosoft, Decatur, GA). Each measurement was performed before, during and after NaLac, mannitol or lactic acid applications. Detected synaptic events were measured for amplitude, decay kinetics and inter-event intervals. The total number of synaptic events was determined, and the corresponding frequency was obtained by dividing the sum of events by the total duration of the segments examined (30s).

Data analysis and statistic. Data were analyzed using Clampex 9.2 software (Molecular Devices Corp.) and MiniAnalysis 6.0 (Synaptosoft). Time constants of membrane charging $\left(\tau_{0}\right)$ were analyzed using Rall's equation (Rall, 1969). Where appropriate, paired $t$-tests for comparing two treatments in the same group, ANOVA with Tukey's test for between-subjects analyses, and Dunnett's post hoc analysis were used to compare the data for within-subjects time effects. All values throughout the paper are presented as average \pm SEM. Significance was indicated with $p<0.05$.

\section{Experiment 3-Colocalization of DMH-Projecting Neurons in the A3Vr with vGlut2 and GAD65 mRNA}

Adult male Sprague-Dawley rats (250-350 g; Harlan, Indianapolis, IN) were maintained in constant temperature/humidity vivarium quarters, with food and water available ad libitum. All protocols for experiment 3 were approved by the University of Cincinnati Institutional Animal Care and Use Committee.

Retrograde tracer injections. Rats were anesthetized with ketamine $(87 \mathrm{mg} / \mathrm{kg})$ and xylazine $(13 \mathrm{mg} / \mathrm{kg})$ and prepared for aseptic stereotaxic surgery. Briefly, the scalp was incised and burr holes drilled in the skull in accordance with the planned injection coordinates. Glass micropipettes (15$10 \mu \mathrm{m}$ tips) filled with $4 \%$ Fluorogold (Fluorochrome) were lowered into place and left in situ for $10 \mathrm{~min}$ before injection. Coordinates for the injections were as follows (Paxinos and Watson coordinates): bregma $-3.12 \mathrm{~mm}$, $0.6 \mathrm{~mm}$ lateral to midline, $8.8 \mathrm{~mm}$ ventral to the dural surface. Fluorogold was ejected by iontophoresis $(2-4 \mu \mathrm{A}$, $7 \mathrm{~s}$ alternating current pulses for $30 \mathrm{~s}$ ). Micropipettes were left in place for $10 \mathrm{~min}$, at which point the burr hole was packed with sterile bonewax and the incision closed with wound clips. Rats were killed 1 week after injection by overdose with pentobarbital $(150 \mathrm{mg} / \mathrm{kg})$ and perfused with $100-150 \mathrm{ml}$ phosphate-buffered saline, followed by $250 \mathrm{ml}$ of $4 \%$ paraformaldehyde. After perfusion, brains were removed and placed in fixative solution for $1 \mathrm{~h}$, after which they were transferred to $30 \%$ sucrose for cryoprotection. Brains were then sectioned at $25 \mu \mathrm{m}$ on a Microm sliding microtome and stored in DEPC-treated cyroprotectant solution.

Preparation of RNA probes. GAD65 and VGlut2 cDNAs were used as templates for riboprobe synthesis. The GAD65 construct was generously provided by $\mathrm{Dr}$ Allan Tobin at UCLA, and the VGlut2 cDNA was generated in this lab by PCR (Ziegler et al, 2005). Probes were transcribed in vitro from linearized plasmid constructs in the presence of ${ }^{35}$ S-UTP and T7 or SP6 RNA polymerase, as described earlier (Seroogy and Herman, 1996). No positive hybridization was observed using sense-strand probes or in antisense riboprobe hybridizations in RNAse A-pretreated tissue sections.

Floating in situ hybridization combined with immunocytochemistry. Before hybridization, free-floating sections were washed $5 \times$ for $5 \mathrm{~min}$ in $50 \mathrm{mM} \mathrm{KPBS}$ and were incubated in blocking buffer (50 mM KPBS, $0.3 \%$ TX-100, $0.2 \% \mathrm{BSA})$ for $1 \mathrm{~h}$ at room temperature. Sections were hybridized overnight at $45^{\circ} \mathrm{C}$ with $4.5 \times 10^{6} \mathrm{cpm}{ }^{35} \mathrm{~S}$ labeled probe $/ 5 \mathrm{ml} /$ well, diluted in hybridization medium $(50 \%$ formamide, $20 \mathrm{mM}$ Tris- $\mathrm{HCl}, \mathrm{pH} 7.5,1 \mathrm{mM}$ EDTA, $335 \mathrm{mM}$ $\mathrm{NaCl}, 1 \times$ Denhardt's, $200 \mu \mathrm{g} / \mathrm{ml}$ salmon sperm DNA, $25 \mu \mathrm{g} /$ $\mathrm{ml}$ yeast tRNA, $20 \mathrm{mM}$ dithiothreitol (DTT), and $10 \%$ dextran sulfate). Tissue was incubated overnight, at which point they were rinsed $2 \times 10 \mathrm{~min}$ in $2 \times$ SSC buffer $(1 \times$ 
$\mathrm{SSC}=0.25 \mathrm{M}$ sodium chloride, $0.015 \mathrm{M}$ sodium citrate, $\mathrm{pH}$ $7.2)$ and treated with RNAse $\mathrm{A}(200 \mu \mathrm{g} / \mathrm{ml})$ for $3 \mathrm{~h}$ at $37^{\circ} \mathrm{C}$. Sections were then washed $1 \times 10 \mathrm{~min}$ in $2 \times \mathrm{SSC}$, $1 \times 10 \mathrm{~min}$ in $1 \times \mathrm{SSC}, 1 \times 10 \mathrm{~min}$ in $0.5 \times$ SSC and incubated for $1 \mathrm{~h}$ at $45^{\circ} \mathrm{C}$ in $0.5 \times \mathrm{SSC}$, followed by a 30 min incubation in blocking buffer at room temperature. The sections were then incubated overnight at $4{ }^{\circ} \mathrm{C}$ with rabbit anti-Fluorogold (FG) primary antibody (courtesy Stan Watson, University of Michigan) diluted in blocking buffer at 1:5000. After incubation, the sections were washed with $50 \mathrm{mM}$ KPBS, $0.02 \% \mathrm{TX}-1005 \times$ for $5 \mathrm{~min}$ at room temperature. The sections were then incubated with affinity-purified biotinylated anti-rabbit IgG made in goat (Vector Laboratories, Burlingame, CA), diluted at $1: 500$ in $50 \mathrm{mM}$ KPBS, $0.02 \% \mathrm{TX}-100$, for $1 \mathrm{~h}$ at room temperature. After incubation, the sections were washed in $50 \mathrm{mM}$ KPBS, $0.02 \%$ TX-100 $5 \times$ for $5 \mathrm{~min}$, followed by an incubation in Vectastain ABC Solution (Vector Laboratories), diluted in $50 \mathrm{mM}$ KPBS, $0.1 \%$ BSA at $1: 1000$, for $1 \mathrm{~h}$ at room temperature. After incubation, the sections were washed in $50 \mathrm{mM} \mathrm{KPBS}, 0.02 \% \mathrm{TX}-1005 \times$ for $5 \mathrm{~min}$. The sections were stained with 3,3'-diaminobenzidine (DAB) by incubating the sections in $\mathrm{DAB}(0.4 \mathrm{mg} / \mathrm{ml}$ in $50 \mathrm{mM}$ KPBS $)$ with hydrogen peroxide $(0.167 \mu \mathrm{l}$ of $30 \% / \mathrm{ml} 50 \mathrm{ml} \mathrm{KPBS})$. The sections were then washed in $50 \mathrm{mM}$ KPBS, $0.02 \% \mathrm{TX}-100$ $5 \times$ for $5 \mathrm{~min}$, then mounted on glass slides in $50 \mathrm{mM} \mathrm{KPB}$, $1.5 \%$ gelatin. Subsequently, the slides were coated with Kodak photographic emulsion NTB2, diluted 1:1 with water, air-dried, and stored at $4{ }^{\circ} \mathrm{C}$ in a light- and humidfree environment for 4 weeks. After development in Kodak D-19 developer and Rapid Fix solutions, emulsion-dipped sections were dehydrated, and cover-slipped using DPX mountant (Fluka, Milwaukee, WI).

Imaging. Emulsion-dipped DAB-stained slides were photographed with an Axioplan 2 microscope (Zeiss, Thornwood, $\mathrm{N} 23 \mathrm{Y}$ ). Cells were analyzed for double-positive labeling of FG DAB staining with GAD67 or VGlut2 grains. Doublepositive cells were visualized by grains overlying FG-positive cell profiles. For a cell to be considered double-labeled, grain densities overlying the cell had to be at least five times that of an equivalent background region.
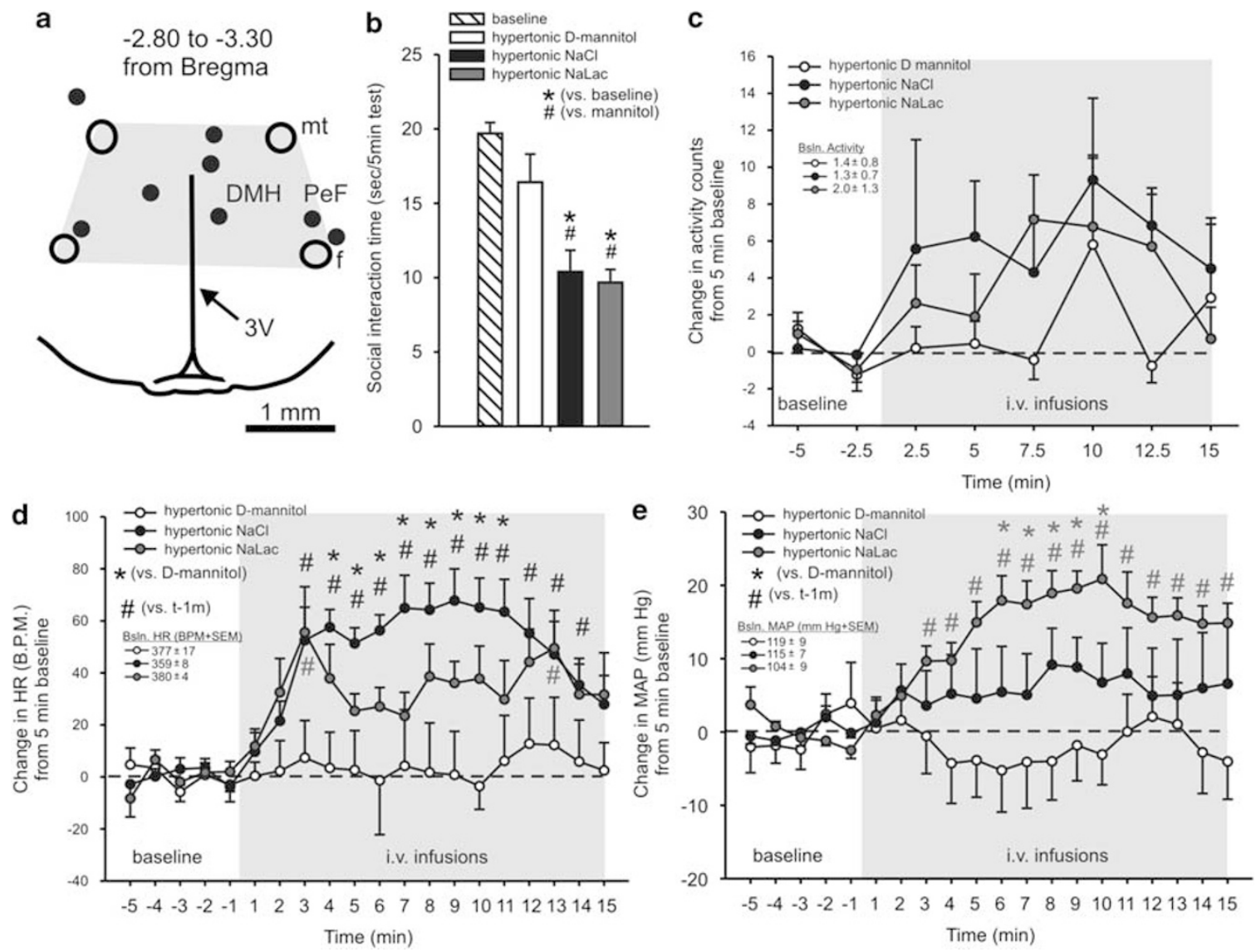

Figure I Experiment I: the effects of intravenously infusing panic-prone rats (ie, with previous infusions of the GABA synthesis inhibitor (L-allylglycine: L-AG) into the dorsomedial hypothalamus (DMH)) with hypertonic (0.5 M) D-mannitol, sodium chloride ( $\mathrm{NaCl}$ ), or sodium lactate (NaLac) on 'anxiety'- and 'flight'-associated behavior and cardiovascular responses. (a) Illustration of osmotic minipump placements in the DMH from -3.30 to $-2.80 \mathrm{~mm}$ from the bregma. Black circles represent histological placements of the minipumps residing in the DMH in which the I-AG infusions occurred. The bar graph in (b) illustrates the effects of the different i.v. infusions on the duration of social interaction (SI) in an open field as compared with pre-I-AG baseline data. Line graphs illustrate changes in (c) general activity counts, (d) heart rate (HR in beats/min (BPM)) comparing baseline values (pre-i.v. infusion) with values measured post-i.v. infusion, and (e) mean arterial blood pressure (MAP in $\mathrm{mm} \mathrm{Hg}$ ). There was no significant baseline HR, MAP, or activity between groups (see the legends in the figures with baseline HR, MAP and activity \pm SEM). Values of bars or lines represent the mean, whereas error bars represent SEM. Mean values of baseline MAP, RR, and HR + SEM are listed in the legend for each group. Abbreviations: $3 \mathrm{~V}$, third ventricle; $\mathrm{f}$, fornix; mt, mammillothalamic tract, PeF, perifornical nucleus. 


\section{RESULTS}

Experiment 1 -Effects of i.v. Infusions on

Panic-Associated Behavior and Cardiovascular

Responses in Rats Made Panic-Prone with L-AG

All minipump cannulae placements resided in regions of the DMH known to be cardioexcitatory (Johnson and Shekhar, 2006; Shekhar et al, 1987) (Figure 1a). Some tissue damage at the site of implantation was noted, but this damage was minimal and was equal in the control and experimental groups, with the majority of cells in the $\mathrm{DMH} / \mathrm{PH}$ still intact surrounding the infusion site stained with methyl green.

Rats with $\mathrm{L}-\mathrm{AG}$ infusions into the $\mathrm{DMH}$ for 5 days had less SI (an anxiogenic effect) in the SI test measured immediately after a $20 \mathrm{~min}$ i.v. infusion of either $\mathrm{NaLac}$ or $\mathrm{NaCl}$, but D-mannitol, compared with pre-pump baseline behavior ( (Figure 1b) and i.v. infusion effect $\left(\mathrm{F}_{(3,16)}=13.4, p<0.001\right)$ + Tukey's HSD post hoc test).

For general activity, between-subjects analyses did not detect an overall i.v. infusion $\mathrm{x}$ time interaction (Figure $1 \mathrm{c}$, $\left.\mathrm{F}_{(14,98)}=0.7, p=0.779\right)$. However, between-subjects analyses revealed that challenging panic-prone rats (ie, L-AG pretreated) with $\mathrm{NaLac}$ or $\mathrm{NaCl}$, but not D-mannitol, elicited a tachycardia response (Figure 1d; i.v. infusion $\times$ time interaction $\left(\mathrm{F}_{(38,247)}=2.1, p=0.001\right)+$ Tukey's HSD post hoc test), whereas only NaLac elicited a pressor response activity (Figure 1e; i.v. infusion $\times$ time interaction; $\left(\mathrm{F}_{(38,266)}=2.6, \quad p<0.001\right)+$ Tukey's HSD post hoc test $)$. One animal was removed from D-mannitol analyses because of a low battery on the telemetry probe that showed MAP responses outside of the physiological range.

Within-subjects analyses revealed that challenging L-AGpretreated rats with NaLac increased in MAP (time effect, $\mathrm{F}_{(19,100)}=9.3, p<0.001+$ Dunnett's test) and HR (time effect, $\mathrm{F}_{(19,100)}=2.8, p=0.001+$ Dunnett's test) from baseline, but did not alter general activity (time effect, $\mathrm{F}_{(7,40)}=1.8, p=0.112$ ) over time after infusions. Challenging L-AG-pretreated rats with $\mathrm{NaCl}$ increased $\mathrm{HR}$ (time effect, $\mathrm{F}_{(19,100)}=8.3, p<0.001+$ Dunnett's test) but not MAP (time effect, $\mathrm{F}_{(19,100)}=0.4, p=0.993$ ) or general activity (time effect, $\mathrm{F}_{(7,40)}=1.0, p=0.454$ ) over time. Challenging L-AG-pretreated rats with D-mannitol had no effect on HR (time effect, $\mathrm{F}_{(19,80)}=0.1, p=1.000$ ), MAP (time effect, $\mathrm{F}_{(19,80)}=0.1, p=1.000$ ), or general activity (time effect, $\mathrm{F}_{(7,32)}=0.9, p=0.523$ ) over time. There were no differences in baseline $\operatorname{HR}\left(\mathrm{F}_{(2,14)}=1.3, p=0.305\right)$, MAP $\left(\mathrm{F}_{(2,14)}=0.8, p=0.457\right)$, or activity $\left(\mathrm{F}_{(2,14)}=0.1, p=0.877\right)$ among treatment groups (see Figures $1 \mathrm{c}-\mathrm{e}$ for baseline values).

\section{Experiment 2-In Vitro Electrophysiology}

Localization of DMH-projecting neurons in A3Vr and site of injection. The injection site of the fluorescent microbeads was limited to the $\mathrm{DMH}$ but not restricted to any specific subregion therein (Figures $2 \mathrm{a}$ and $\mathrm{b}$ for an illustration of injection sites; and Figures $2 \mathrm{c}$ and $\mathrm{d}$ for photographs). Our preliminary experiments had shown that the highest numbers of labeled cells in the mPOA/OVLT area were obtained with injections centered in the 'zona compacta' of the DMH. Virtually, all labeled neurons were ipsilateral with respect to the injection site of the tracer in a

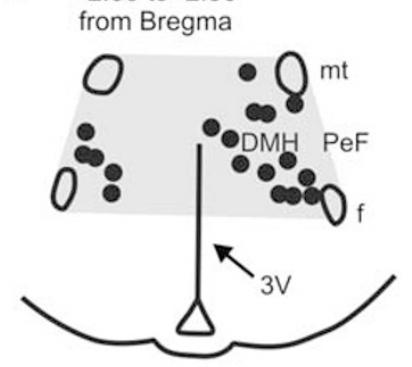

C

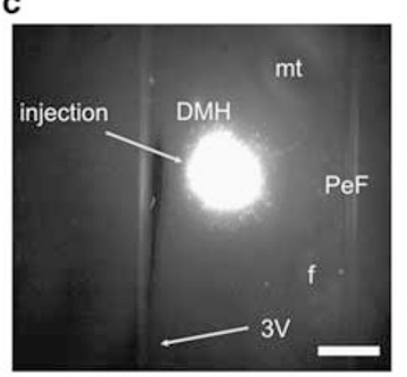

$-3.12 \mathrm{~mm}$ from Bregma

e

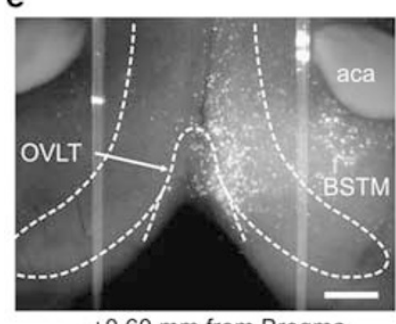

$+0.60 \mathrm{~mm}$ from Bregma b $\quad-2.80$ to -3.30

from Bregma

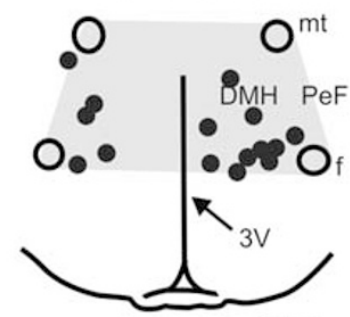

$1 \mathrm{~mm}$

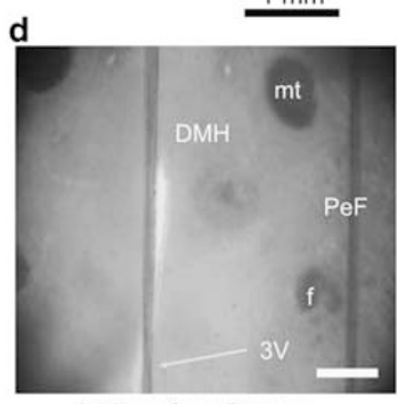

$-3.12 \mathrm{~mm}$ from Bregma

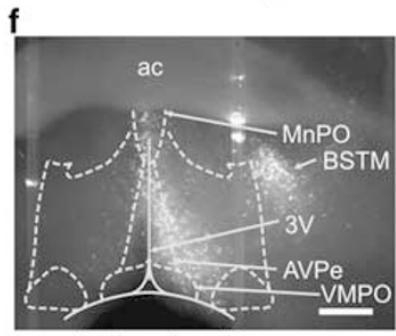

$-0.12 \mathrm{~mm}$ from Bregma
Figure 2 Illustration of osmotic minipump placements in the DMH from (a) -2.30 to $-2.56 \mathrm{~mm}$ and (b) from -3.30 to $-2.80 \mathrm{~mm}$ from the bregma with $1 \mathrm{~mm}$ scale bar in (b). Black circles represent histological placements of the minipumps residing in the DMH in which the L-AG infusions occurred. Photomicrographs depicting typical fluorescent microbeads distribution in the hypothalamus of the live brain slice image. (c) Low-power view (fluorescent mode, $\times 40$ magnification) of a hypothalamic brain slice containing the dorsomedial hypothalamus (DMH). (d) The same injection site in the $\mathrm{DMH}$ region in infrared-differential contrast mode. (e, f) Low-power view (fluorescent mode, $\times 4$ ) showing a fluorescent image of the largely ipsilateral distribution of microbeads containing cell bodies within and around the within OVLT and MnPO regions of the live brain slice at a rostral (c) and caudal (d) level. Abbreviations: $3 \mathrm{~V}$, third ventricle; ac, anterior commissure; $\mathrm{AVPe}$, anteroventral periventricular nucleus; BSTM, bed nucleus of the stria terminalis, medial part; $\mathrm{DMH}$, dorsomedial hypothalamus; f, fornix; $\mathrm{MnPO}$, median preoptic nucleus; mt, mamillothalamic tract; OVLT, organum vasculosum laminae terminalis; PeF, perifornical hypothalamus; VMPO, ventromedial preoptic nucleus. Scale bars in bottom right of photos are $0.5 \mathrm{~mm}$.

DMH (see Figures $2 \mathrm{c}$ and d). Neurons in the OVLT and MnPO that project to the DMH and so contained fluorescent microbeads were then visualized in the living slice using epifluorescence. The highest number of labeled neurons was in the $\mathrm{A} 3 \mathrm{Vr}$, including the ventromedial, medial and median areas of the preoptic area, and the vascular organ of lamina terminalis based on coordinates given in a standard atlas of the rat brain (Paxinos and Watson, 2005) (see Figures $2 \mathrm{e}$ and $\mathrm{f}$ ). We also noticed a large number of labeled cells in the fusiform, medial ventral, 
and lateral posterior parts of the bed nucleus of stria terminalis, as well as in the parastrial nucleus and lateral superior olive (see Figures $2 \mathrm{e}$ and $\mathrm{f}$ ).

Membrane characteristics of $\mathrm{A} 3 \mathrm{Vr}$ cells projecting to the $D M H$. In this study, we report on the physiological properties of 33 neurons in the A3Vr retrogradely labeled with fluorescent microbeads injected into the DMH. Neurons were retained for analysis only if they had a resting membrane potential more negative than $-55 \mathrm{mV}$, and an action potential amplitude that overshot $0 \mathrm{mV}$ by $>5 \mathrm{mV}$.

An examination of the passive membrane properties revealed that labeled neurons in the $\mathrm{A} 3 \mathrm{Vr}$ had a $\mathrm{Vm}=-57 \pm 0.4 \mathrm{mV}$, an $\mathrm{Rm}=757.7 \pm 46.9 \mathrm{M} \Omega$, and a $\tau_{0}=25.5 \pm 1.6 \mathrm{~ms}$. Moreover, action potentials generated by a transient $(350 \mathrm{~ms})$ depolarizing current injection (10$50 \mathrm{pA}$ ), and recorded at holding potential of $-60 \mathrm{mV}$ had a mean amplitude of $75.7 \pm 1.1$, the rise time $-2.3 \pm 0.03 \mathrm{~ms}$, the half-width $-1.4 \pm 0.05 \mathrm{~ms}$, the decay time $-0.7 \pm$ $0.02 \mathrm{~ms}$ (Figure 3 ).

Effect of NaLac, lactic acid and D-mannitol on the properties of $\mathrm{A} 3 \mathrm{Vr}$ cells. We examined the effects of exogenous application of NaLac $(20 \mathrm{mM})$ on the physiological properties of 12 labeled $\mathrm{A} 3 \mathrm{Vr}$ cells. In the presence of NaLac, the cells showed a significant increase in firing rate (control: $13.1 \pm 6.5$ spikes/min; NaLac: $103.4 \pm 38$ spikes/ min, $\mathrm{F}_{(2,35)}=3.3, p<0.05, n=12$, one-way ANOVA + Dunnett's test) that was associated with membrane depolarization $(\mathrm{Vm}=4.8 \pm 0.5 \mathrm{mV}$; Figures $4 \mathrm{a}$ and $\mathrm{b})$. The increase in firing rate was accompanied by a significant increase in the input resistance (control: $995.4 \pm 133.8 \mathrm{~m} \Omega$, NaLac: $1219 \pm 154.1 \mathrm{~m} \Omega, t_{(11)}=2.9, p<0.05, n=12$, paired $t$-test; Figure $4 \mathrm{c}$ ).

Next, we examined the spontaneous activity response of $\mathrm{A} 3 \mathrm{Vr}$ neurons to NaLac, because it can be one of the possible mechanisms that control the firing of the $\mathrm{A} 3 \mathrm{Vr}$ neurons. The exposure to NaLac significantly altered the amplitude (control: $2.8 \pm 0.04 \mathrm{mV}$, NaLac: $3.1 \pm 0.06 \mathrm{mV}$, $t_{(11)}=5.4, p<0.0001, n=12$, paired $t$-test; Figure $4 \mathrm{~d}$ ), but not the frequency (inter-event interval control: $1.4 \pm 0.06 \mathrm{~s}$, NaLac: $1.5 \pm 0.06 \mathrm{~s}, t_{(11)}=1.3, p=0.2, n=12$, paired $t$-test; Figure 4e) of sEPSP, which suggests that the effect of NaLac was postsynaptic.

A potential mechanism underlying the NaLac response can be that cells in the $\mathrm{A} 3 \mathrm{Vr}$ region might be sensitive to altered levels of energy metabolites such as lactate from an i.v. hypertonic NaLac challenge (Shekhar et al, 1997). Therefore, $20 \mathrm{mM}$ lactic acid was applied to cells in the A3Vr that project to the DMH. Application of lactic acid did not alter the action potential firing rate (control: $44.7 \pm 22.2$ spikes/min, lactic acid: $38.6 \pm 18.6$ spikes $/ \mathrm{min}, \mathrm{F}_{(2,32)}=1.5$, $p=0.25, n=11$, repeated one-way ANOVA + Dunnett's test; Figures $5 \mathrm{a}$ and $\mathrm{b}$ ). Application of lactic acid caused membrane hyperpolarization $(\Delta \mathrm{Vm}=3.6 \pm 1.0 \mathrm{mV})$ that was associated with a significant reduction in the input resistance (control: $860.9 \pm 112.7 \mathrm{M} \Omega$; lactic acid: $389.0 \pm 87.5 \mathrm{M} \Omega, t_{(10)}=3.6, p<0.05, n=11$, paired $t$-test; Figure 5c). Surprisingly, lactic acid significantly increased the amplitude (control: $6.1 \pm 0.2 \mathrm{mV}$, lactic acid: $7.9 \pm 0.4 \mathrm{mV}, \quad t_{(10)}=2.5, \quad p<0.05, \quad n=11$, paired $t$-test; Figure 5d) but did not affect the frequency (inter-event interval control: $2.7 \pm 0.1 \mathrm{~s}$; lactic acid: $2.7 \pm 0.1 \mathrm{~s}, t_{(10)}=1.0$, $p=0.3, n=11$, paired $t$-test; Figure 5e) of sEPSPs, which suggests that the effect of lactic acid was also postsynaptic.

Another potential mechanism underlying the NaLac sensitivity of A3Vr neurons may be the osmotic modulation of cell volume. Changes in cell volume, secondary to osmotic perturbations, have been shown to modulate the activity of a non-selective-cation conductance, leading to membrane depolarization and an increase in firing frequency as extracellular osmolality is increased (Bourque et al, 1994; Oliet and Bourque, 1993). Perfusing DMHprojecting $\mathrm{A} 3 \mathrm{Vr}$ neurons with $40 \mathrm{mM}$ D-mannitol perfusion did not alter the frequency of the action potential firing rate (control: $4.1 \pm 2.5$ spikes/min, D-mannitol: $20 \pm 12.6$ spikes/ min, $\mathrm{F}_{(2,29)}=1.5, p=0.2, n=10$, one-way ANOVA + Dunnet's post-test, Figures $6 \mathrm{a}$ and b). ACSF containing $40 \mathrm{mM}$
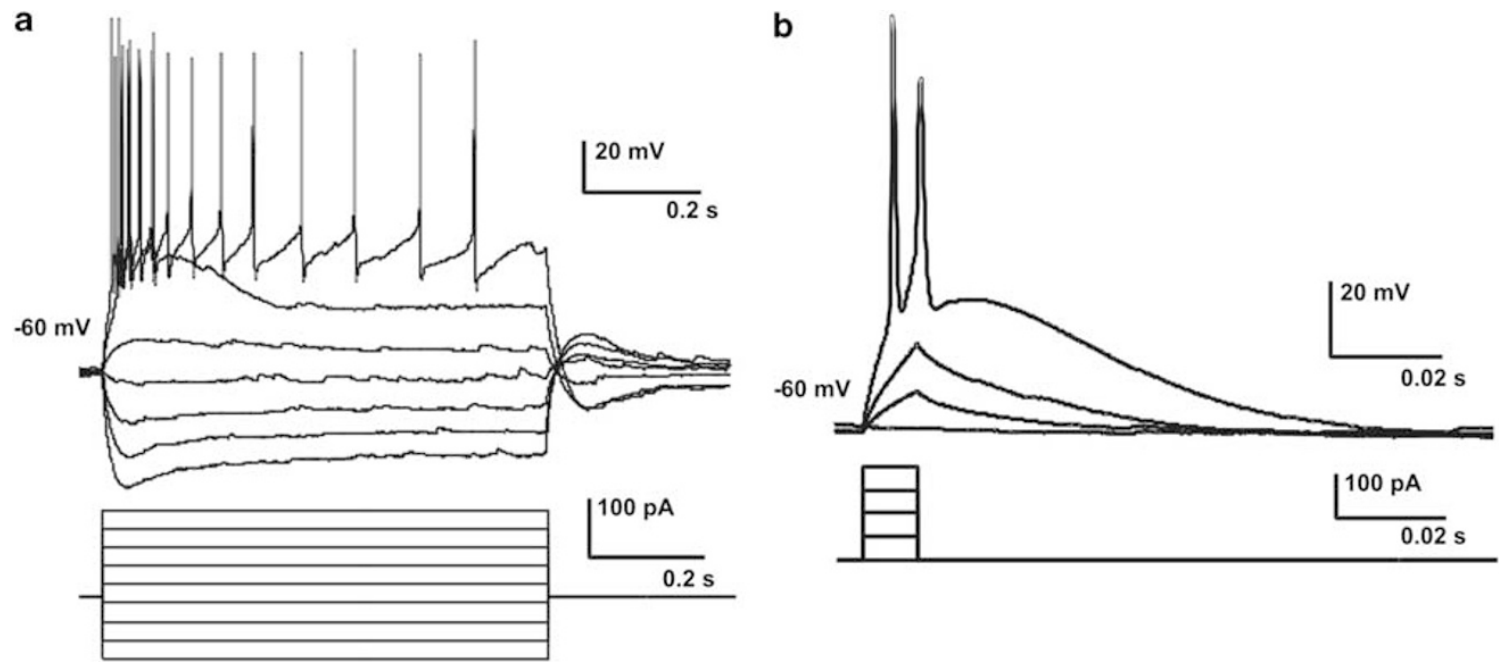

Figure 3 Whole-cell recordings from the neurons located in the $\mathrm{A} 3 \mathrm{Vr}$ (ie, OVLT and MnPO) that also project to the DMH. (a) Current-clamp traces showing the voltage response of a typical $\mathrm{DMH}$-projecting $\mathrm{A} 3 \mathrm{Vr}$ neuron to transient depolarizing and hyperpolarizing current injection; (b) typical currentclamp recording of action potentials evoked by short current injection in a $\mathrm{DMH}$-projecting $\mathrm{A} 3 \mathrm{Vr}$ neuron. 


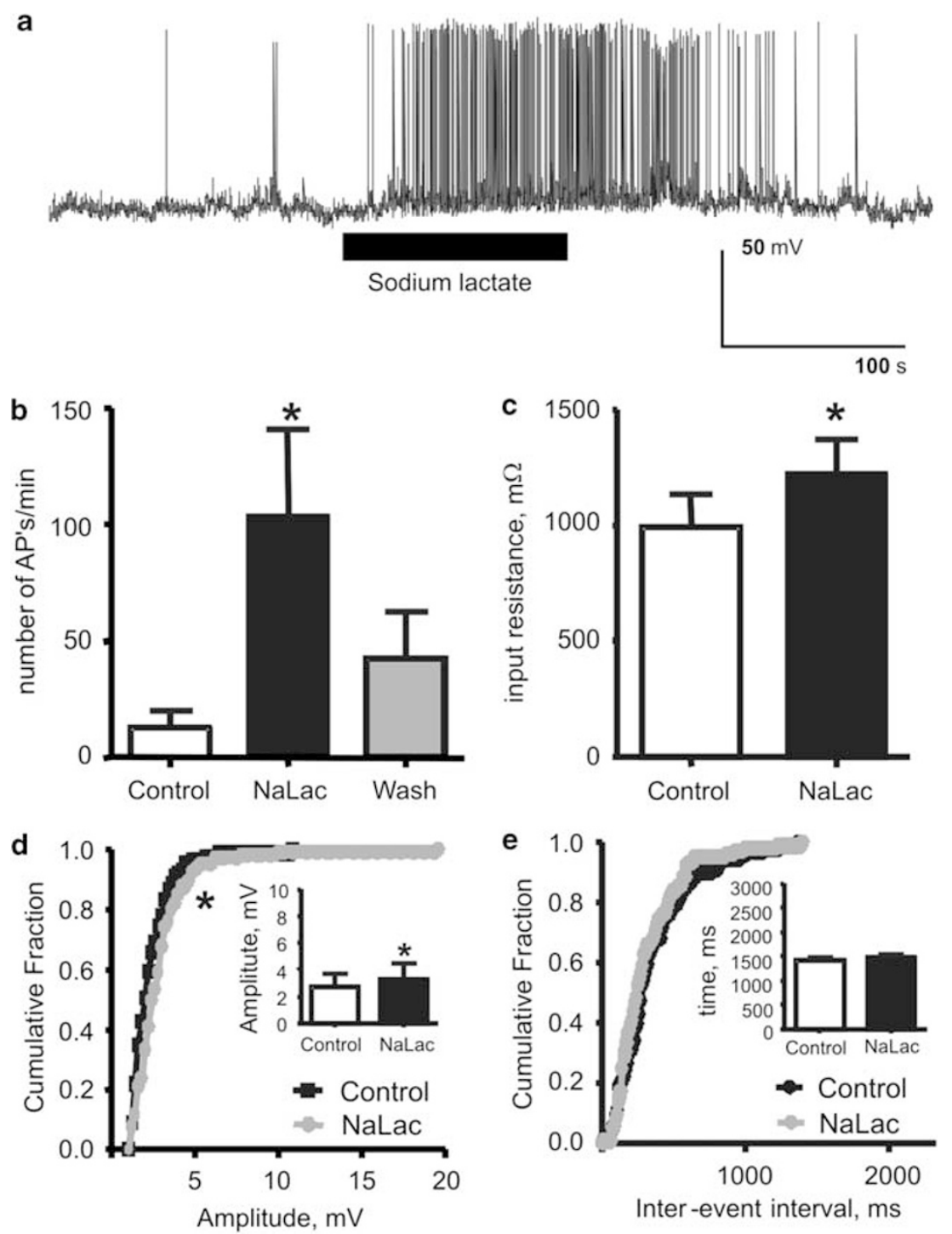

Figure 4 Effect of $\mathrm{NaLac}$ on membrane potential, input resistance, number of action potentials, and sEPSP of neurons in the A3Vr that project to the $\mathrm{DMH}$. (a) Solution bath application of NaLac $(20 \mathrm{mM})$ in ACSF to a non-spontaneously active (at holding potential $-60 \mathrm{mV}$ ) neuron in the A3Vr induced an early small membrane depolarization and increase in spontaneous firing rates. Bath applications of $20 \mathrm{mM}$ NaLac to non-spontaneously and spontaneously active neurons in the $\mathrm{A} 3 \mathrm{Vr}$ (b) increased the number of action potentials (APs)/min, and (c) increased the input resistance. The exposure to NaLac significantly altered the (d) amplitude, but not the (e) frequency of sEPSP. (d, e) Graphs of cumulative fraction of sEPSP from single cell and plotted as a function of amplitude (d) or inter-event interval (e). Insets depict average changes in amplitude and inter-event interval. Data in graphs of (b-e) are presented as mean \pm SEM. $* p<0.05$ vs control, ${ }^{*} p<0.05$ vs NaLac perfusion $(n=12)$.

D-mannitol also had no effect on the input resistance of DMH-projecting A3Vr neurons (control: $606.6 \pm 129.2 \mathrm{~m} \Omega$, D-mannitol: $576.4 \pm 119.7 \mathrm{~m} \Omega, \quad t_{(9)}=0.3, p=0.8, \quad n=10$, paired $t$-test, Figure $6 \mathrm{c}$ ). Nor did D-mannitol have an effect on the amplitude (control: $2.3 \pm 0.06 \mathrm{mV}$; D-mannitol: $2.3 \pm 0.06 \mathrm{mV}, \quad t_{(9)}=0.7, \quad p=0.5, \quad n=10$, paired $t$-test, Figure 6d)) or frequency (inter-event interval control: $1.8 \pm 0.06 \mathrm{~s}, \quad$ D-mannitol: $1.9 \pm 0.07 \mathrm{~s}, \quad t_{(9)}=0.8, \quad p=0.4$, $n=10$, paired $t$-test; Figure 6e) of the sEPSPs in the A3Vr neurons in response to D-mannitol application.

\section{Experiment 3 - Colocalization Of DMH-Projecting Neurons in the A3Vr With vGlut2 and GAD65 mRNA}

Immunocytochemistry for FG on coronal brain sections of the hypothalamus showed that injection sites were restricted to the DMH, with diffuse FG immunoreactivity surrounding the injection site that was also largely restricted to the DMH (see Figure 7a). The area of the $\mathrm{DMH}$ is roughly square in dimension, with the corners being the mammillothalamic tract, the fornix, the top of the third ventricle, and the halfway down the third ventricle (immediately medial from the fornix) and is particularly sensitive to BMI-induced cardioexcitatory response (Samuels et al, 2004) and receives projections from $\mathrm{A} 3 \mathrm{Vr}$ near the OVLT (Thompson and Swanson, 1998). Analyses of retrograde labeling revealed that numerous FG-positive neurons were evident in the MnPO and fewer in the OVLT, consistent with projections to the DMH (Figures $7 \mathrm{~b}-\mathrm{d}$ ). In situ hybridization for vGlut2 or GAD65 on alternate FG immunostained brain sections revealed strong vGlut2 mRNA hybridization (as evidenced by silver grains) and 

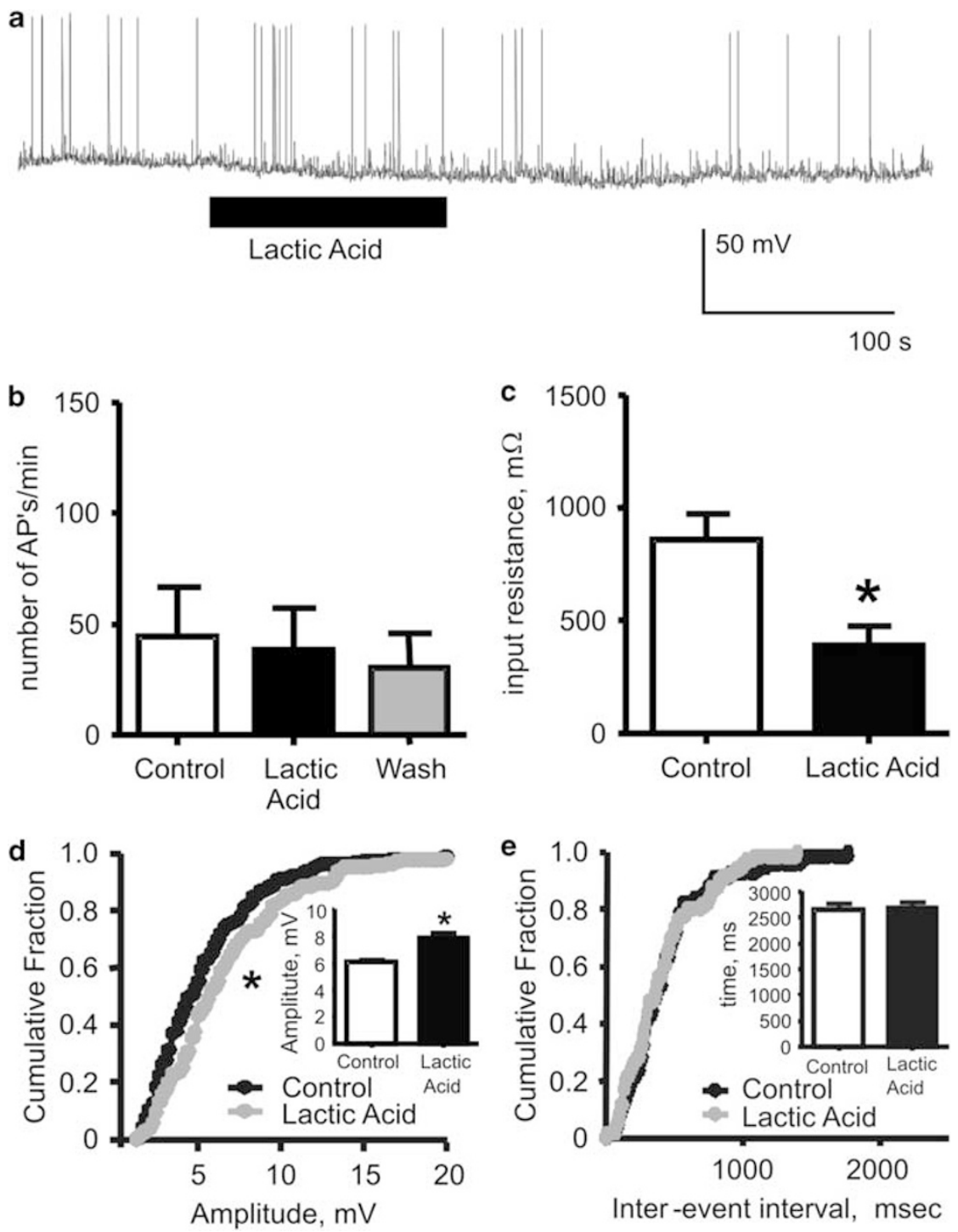

Figure 5 Effect of lactic acid on membrane potential, input resistance, number of action potentials, and on sEPSP of neurons in the A3Vr that project to the DMH. (a) Kreb's solution bath application of lactic acid $(20 \mathrm{mM})$ to a spontaneously active (at holding potential $-60 \mathrm{mV}$ ) neuron in the A3Vr induced only a small membrane hyperpolarization and did not affect firing properties. Bath applications of $20 \mathrm{mM}$ lactic acid to non-spontaneously and spontaneously active neurons in the $\mathrm{A} 3 \mathrm{Vr}$ (b) did not alter the number of action potentials (APs)/min, (c) but did decrease input resistance. The exposure to lactic acid significantly alters the (d) amplitude, but not the (e) frequency of sEPSP. (d, e) Graphs of cumulative fraction of sEPSP from single cell and plotted as a function of amplitude (d) or inter-event interval (e). Insets depict average changes in amplitude and inter-event interval. Data in graphs of (b-e) are presented as mean \pm SEM. $* p<0.05$ vs control, ${ }_{p} p<0.05$ vs NaLac perfusion $(n=12)$. Data in graphs of $(b-e)$ are presented as mean \pm SEM. $* p<0.05$ vs control $(n=10)$.

weak GAD65 mRNA hybridization in the MnPO (panels 1-2 of Figures 7c and d), and weak vGlut2 and GAD65 mRNA hybridization in the OVLT (see panels 3-4 of Figures 7c and d). Within the MnPO, numerous FG/vGlut2 labeled neurons were observed (panels 1-2 of Figure 7c), but no FG/GAD65 labeled neurons (panels 1-2 of Figure $7 \mathrm{~d}$ ). Within the OVLT, a few FG/vGlut2-labeled neurons were observed (panels 3-4 of Figure 7c) and no FG/GAD65-labeled neurons were apparent (panels 3-4 of Figure 7d).

\section{DISCUSSION}

When the panicogenic effects of the three sensory components of the NaLac challenge (ie, changes in sodium, lactate, or osmotic stress) were assessed in panic-prone rats, both i.v. infusions of hypertonic $(0.5 \mathrm{M})$ solutions of $\mathrm{NaCl}$ and NaLac, but not D-mannitol resulted in panic-like behavioral and cardiovascular responses. These results support the hypothesis that sodium, and not osmolarity or lactate, is the critical panic-provoking component of an NaLac challenge. In a subsequent study, applications of exogenous hypertonic $(0.5 \mathrm{M}) \mathrm{NaLac}$ onto DMH-projecting $\mathrm{A} 3 \mathrm{Vr}$ neurons increased the firing rates. These in vitro results further strengthen our previous studies, showing the role of the $\mathrm{A} 3 \mathrm{Vr}$ using in vivo pharmacological (Shekhar et al, 1997) and functional immunocytochemical studies (Johnson et al, 2008) as the initial NaLac 'sensing' structure in the brain in this model of panic disorder.

To clarify further the mechanism through which NaLac might elicit such an increase in electrical activity of the 

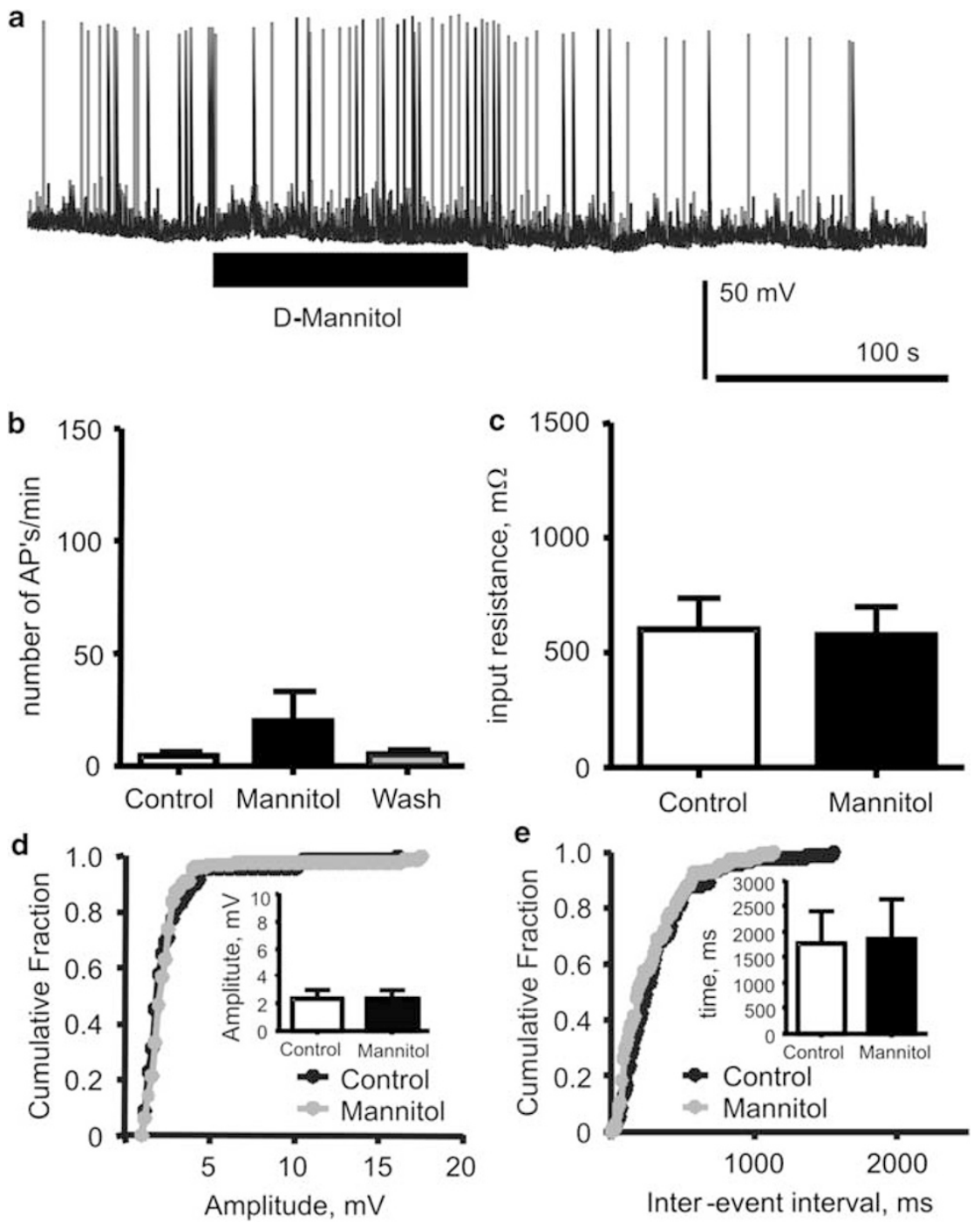

Figure 6 Effects of D-mannitol on membrane potential, input resistance, number of action potentials and on sEPSP of neurons in the A3Vr that project to the DMH. (a) Bath application of D-mannitol $(20 \mathrm{mM})$ to a spontaneously active (at holding potential $-60 \mathrm{mV}$ ) neuron in the A3Vr. Bath applications of $20 \mathrm{mM}$ D-mannitol to non-spontaneously and spontaneously active neurons in the A3Vr (b) did not alter the number of action potentials (AP's)/min, (c) or alter the input resistance. The exposure to D-mannitol did not significantly alter the (d) amplitude, or the (e) frequency of sEPSP. (d, e) Graphs of cumulative fraction of sEPSP from single cell and plotted as a function of amplitude (d) or inter-event interval (e). Inserts depict average changes in amplitude and interevent interval. Data in graphs of $(b-e)$ are presented as mean \pm SEM. $(n=\mid I)$.

DMH-projecting A3Vr neurons, we performed additional experiments in which NaLac was replaced with D-mannitol or lactic acid. Our results appeared to rule out the possibility that mechanoreceptors are activated by the hyperosmolarity of the NaLac to induce panic, because increasing the osmolality of the bathing solution by inclusion of D-mannitol elicited no measured electrophysiological changes in $\mathrm{A} 3 \mathrm{Vr}$ neurons that project to the $\mathrm{DMH}$. We also tested the hypothesis that neurons in $\mathrm{A} 3 \mathrm{Vr}$ might be excited by lactic acid. However, although extracellular application of lactic acid induced small membrane hyperpolarization, the firing rates of neurons in the $\mathrm{A} 3 \mathrm{Vr}$ that project to the $\mathrm{DMH}$ were unaltered. These data suggest that lactic acid is not excitatory, but rather is inhibitory to $\mathrm{A} 3 \mathrm{Vr}$ neurons projecting to the $\mathrm{DMH}$. Together, our in vitro data show that NaLac perfusions are excitatory to $\mathrm{A} 3 \mathrm{Vr}$ neurons that project to the $\mathrm{DMH}$, whereas lactic acid has the opposite effect.
The in vivo finding that challenging a panic-prone rat with hypertonic $\mathrm{NaCl}$ or NaLac elicits equivalent panic-like responses suggests that $\mathrm{Na}+$ is the critical sensory component. The in vitro evidence suggests that the changes in the concentration of $\mathrm{Na}+$ are exciting neurons in the $\mathrm{A} 3 \mathrm{Vr}$ that release excitatory neurotransmitters (eg, glutamate) onto postsynaptic receptors expressed on DMH neurons (see the hypothetical illustration in Figure 8). It is well known that microinjection of glutamate analogs such as kainic acid or $\mathrm{GABA}_{\mathrm{A}}$ receptor antagonists into the $\mathrm{DMH}$ increase HR and blood pressure (De Novellis et al, 1995; DiMicco and Monroe, 1996; Fontes et al, 2001; Soltis and DiMicco, 1991, 1992). In our animal model of panic disorder, we have also shown that challenging panic-prone rats with NaLac increases cellular responses in the $\mathrm{A} 3 \mathrm{Vr}$ alongside increased responses on soma in the DMH that express $N$-methyl-D-aspartic (NMDA)-type glutamate receptors (Johnson and Shekhar, 2006; Johnson et al, 2008). 
a

FG injection in $\mathrm{DMH}$

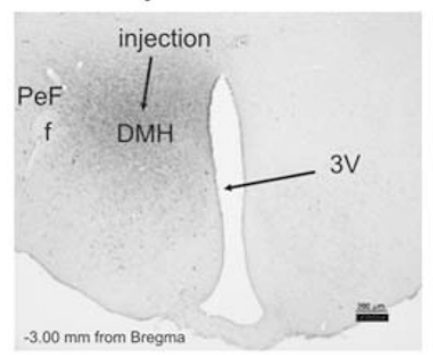

c FG immuno/vGlut2 in situ

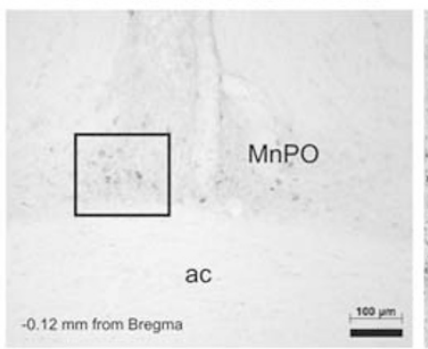

d FG immuno/GAD65 in situ b Regions of OVLTr where DMH projecting neurons were assessed for colocalization with vGlut2 and GAD65

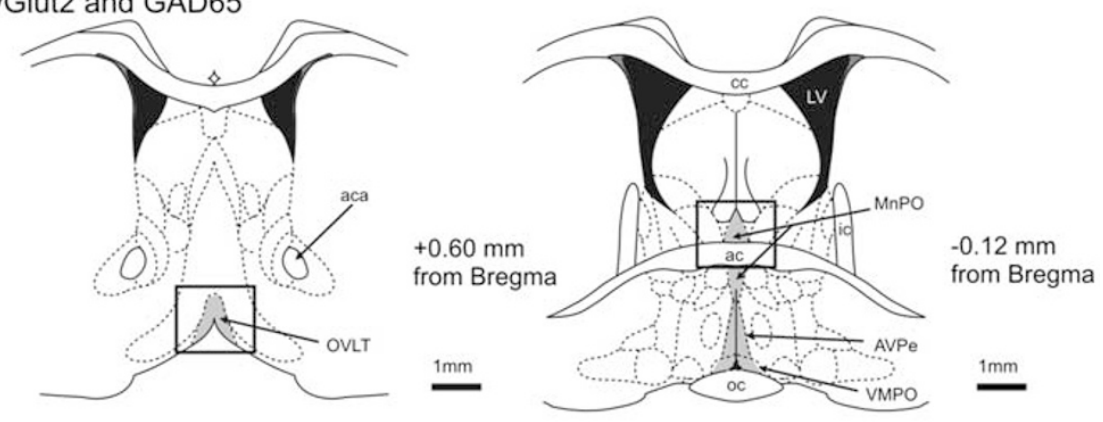

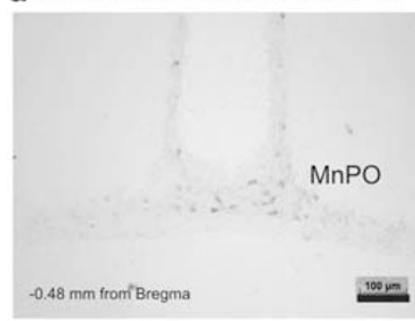
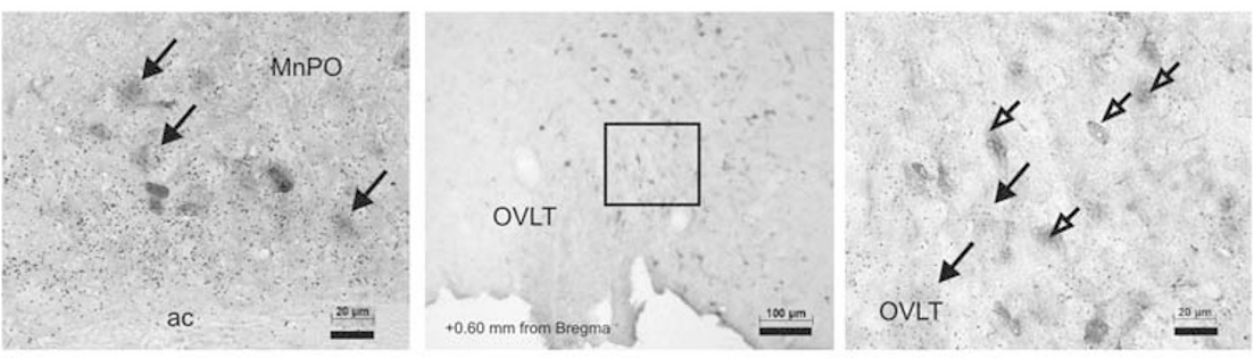

Figure 7 Colocalization of DMH-projecting neurons (fluorogold immunoreactive $(F G+)$ ) in the $A 3 \mathrm{Vr}$ with local in situ hybridization for vGlut2 and GAD65 mRNA. (a) Photomicrograph of FG immunostaining in the DMH after a local FG injection (see the diffuse dark gray staining at injection site); (b) illustrations of two rostrocaudal coronal brain sections from a standard stereotaxic atlas of the rat brain () depicting regions of $\mathrm{A} 3 \mathrm{Vr}$ in which $\mathrm{DMH}$ projecting neurons (FG + ) were assessed for colocalization with vGlut2 and GAD65 mRNA. The gray-shaded region indicates where whole-cell patch clamping was carried out on DMH-projecting neurons, and boxes indicate which photographs were taken for MnPO (left) and OVLT (right) in Figures $6 \mathrm{c}$ and $d$. Photomicrographs in Figures $6 c$ and $d$ show DMH/PeF-projecting neurons (FG +, see diffuse somatic staining) in relation to (c) vGlut2 and (d) GAD65 mRNA (silver grains) in the A3Vr (ie, MnPO (low- and high-magnification photographs respectively in the first two panels), and the OVLT (low- and high-magnification photographs respectively in the last two panels). Boxes in the low-magnification photographs indicate where the high-magnification photographs to the immediate right were taken. Closed arrows indicate FG colocalization with vGlut in Figure 6c. Open arrows in Figure 6c and d indicate FG single-labeled neurons. Additional abbreviations: ac, anterior commissure. Scale bars at the bottom right of the photographs in (a) are $200 \mu \mathrm{m}$; and in (b) and (c) are 100,20, 100 and $20 \mu \mathrm{m}$ in the photographs from left to right.

Furthermore, injecting panic-prone rats with either NMDA antagonists into the DMH (Johnson and Shekhar, 2006) or reducing glutamate release through systemic injections of group 2/3 metabotropic glutamate agonists (Shekhar and Keim, 2000) blocks NaLac-induced panic-like cardiovascular and behavioral responses. Taken together, these data further support the hypothesis that increased sodium concentrations in the plasma (as a result of hypertonic $\mathrm{NaCl}$ or NaLac challenges) excite $\mathrm{Na}+$ sensitive neurons in the $\mathrm{A} 3 \mathrm{Vr}$ that project to the $\mathrm{DMH}$ and release glutamate onto local NMDA-expressing neurons. In panic-prone rats with reduced local inhibitory GABAergic tone, this glutamate release is sufficient to increase local neuronal responses to initiate panic-like responses. Consistent with this hypothesis, here we determined that many DMHprojecting neurons in the dorsal aspects of the $\mathrm{A} 3 \mathrm{Vr}$ were colocalized with vGlut2. The majority of glutamatergic neurons that also project to the DMH were located in the dorsal $\mathrm{A} 3 \mathrm{Vr}$ (ie, MnPO) with fewer colocalized in the ventral aspects of the A3Vr (ie, OVLT). Conversely, virtually no DMH-projecting neurons in the A3Vr were colocalized with GAD65 in the three animals analyzed.

The exact cellular mechanism by which neurons in the $\mathrm{A} 3 \mathrm{Vr}$ detect changes in sodium concentrations is still not entirely clear, but expression of a specialized sodium $\mathrm{X}$ channel $\left(\mathrm{Na}_{\mathrm{X}}\right)$ has been shown to be critical for drinking behavior associated with salt intake. Compared with wildtype and heterozygous controls, homozygous mice lacking the $\mathrm{Na}_{\mathrm{x}}$ channel fail to cease drinking hypertonic saline solutions after dehydration (Watanabe et al, 2000), and these mice also fail to drink more water after an infusion of hypertonic saline into the ventricles (Hiyama et al, 2004). The expression of the $\mathrm{Na}_{\mathrm{X}}$ channel protein is largely restricted to regions containing CVOs, such as the OVLT (Hiyama et al, 2004; Watanabe et al, 2000). Recently, Grob et al (2004) have shown that neurons in the MnPO region express $\mathrm{Na}_{\mathrm{X}}$ channels that are excited by local application of hypertonic $\mathrm{NaCl}$, but not changes in osmolarity. In these 


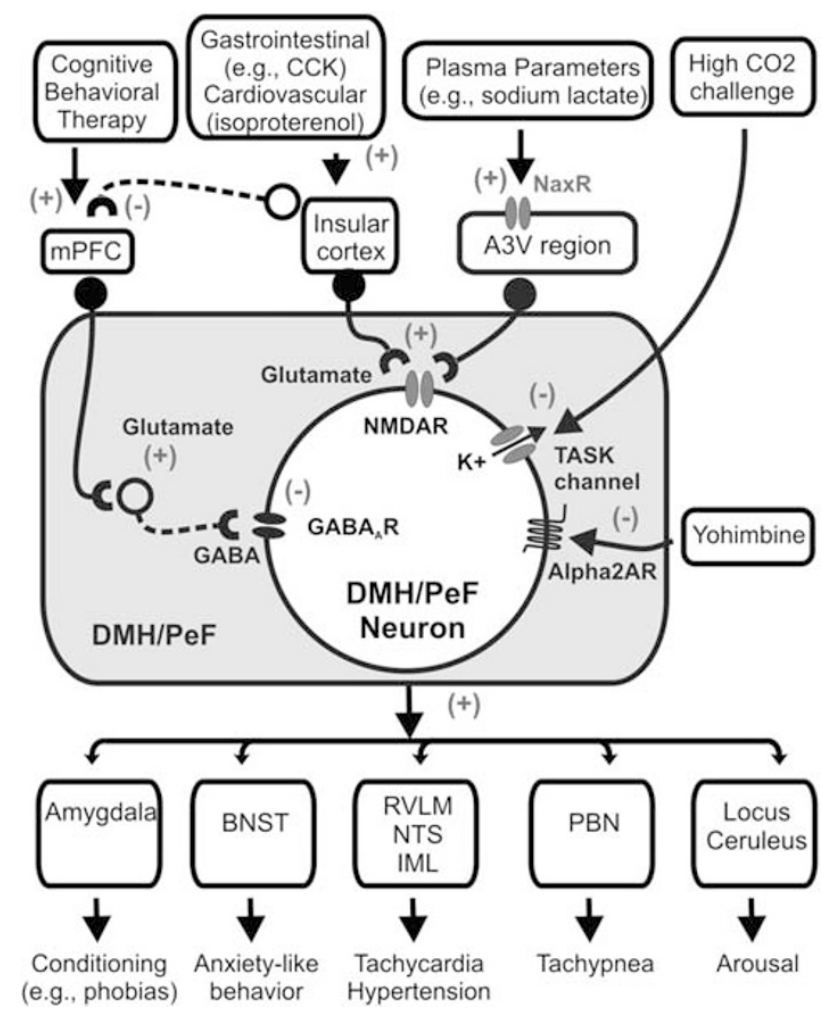

Figure 8 Hypothetical schema of the sensory mechanism by which hypertonic sodium $(\mathrm{Na}+)$ in plasma triggers 'spontaneous' panic-like responses in panic model. Elevated plasma levels of $\mathrm{Na}+$ are 'sensed' by specialized NaX ion channels (Hiyama et al, 2004; Watanabe et al, 2000) that are highly expressed in the median preoptic nucleus (MnPO) (Grob et al, 2004), which is in the anterior third ventricle region ( $\mathrm{A} 3 \mathrm{Vr}$ ) near the organum vasculosum lamina terminalis (OVLT), a forebrain circumventricular organ (eg (Grob et al, 2003; Richard and Bourque, 1992)). On the basis of the data presented here and a previous article (Shekhar et al, 1997), the AV3r contains DMH/PeF-projecting glutamatergic (Glu) neurons, which (after a hypertonic $\mathrm{Na}+$ Challenge) excite the DMH/PeF region to mobilize panic-like responses. GABAergic and glutamatergic neurons are represented by circles attached to dashed or solid lines, respectively. Sources of GABA include local interneurons, which are tonically driven by glutamatergic input from the medial prefrontal cortex (mPFC) (Bard, 1928; Bard and Mountcastle, 1948). This figure also illustrates how other panic-provoking stimuli such as hypercapnia (via $\mathrm{CO}_{2} /$ $\mathrm{pH}$-sensitive $\mathrm{K}+$ channels (TASK) (Williams et al, 2007)), isoproterenol (Balon et al, 1988), cholecystokinin (CCK) (Kobelt et al, 2006), and yohimbine (by inhibiting alpha 2 adrenergic receptors (Singewald et al, 2003)) increase neuronal responses in the DMH/PeF. Afferent targets of the $\mathrm{DMH}$, which are implicated in the regulation of NaLac-induced paniclike responses in this animal model of panic, are also listed (see Johnson et al (2008) for rostrocaudal cellular responses using the animal model of panic presented here, and also the following references: Chamberlin and Saper, 1994; Chen et al, 2004; Fontes et al, 200I;Thompson and Swanson, 1998). Abbreviations: BNST, bed nucleus of the stria terminalis; CBT, cognitive behavioral therapy; IML, intermediolateral cell column of spinal cord; nTS, nucleus of solitary tract; PBN, parabrachial nucleus; RVLM, rostroventrolateral medulla.

studies, the MnPO was where most electrophysiological recordings of DMH-projecting neurons occurred and had the highest concentration of glutamatergic neurons that project to the DMH. Overall, these data are consistent with the hypothesis that $\mathrm{Na}+$ excites glutamatergic neurons in the $\mathrm{A} 3 \mathrm{Vr}$ that project to the $\mathrm{DMH}$ region to elicit panic-responses in panic-prone rats.
Using this panic model, we previously showed that directly injecting a small amount $(100 \mathrm{nl})$ of NaLac into either OVLT or the subfornical organ (SFO) elicited panic-associated cardiorespiratory and behavioral responses, suggesting that the entire $\mathrm{A} 3 \mathrm{Vr}$ (including the $\mathrm{MnPO}$ ) may be involved in sensing NaLac to induce panic responses (Shekhar et al, 1997). In this same article, we also showed that inhibiting the ventral aspect of the $\mathrm{A} 3 \mathrm{Vr}$ near the OVLT using tetrodotoxin (TTX) attenuates the panic responses elicited by i.v. infusions of NaLac (Shekhar et al, 1997). What we have learnt is that all of the afferent fibers from the dorsal A3Vr to the DMH, including those from the SFO and MnPO, also traverse through the ventral A3Vr (Kovacs and Sawchenko, 1993). Thus, injecting TTX into the OVLT, which blocks conduction of local fibers of passage, would essentially disconnect the entire A3Vr from the DMH. Finally, in this study, bath applications of NaLac resulted in rapid (within a few seconds) change in input resistance, which was accompanied by a shift in membrane potential in $\mathrm{MnPO}$ neurons, which provides further evidence of direct effects of NaLac on MnPO neurons.

In addition to hypertonic NaLac, other subthreshold interoceptive stimuli can induce panic attacks in panic disorder patients. For instance, hyperventilation (Gorman et al, 1984), a single breath of air containing $35 \% \mathrm{CO}_{2}$ (Schruers et al, 2002), 5-min exposure to elevated (5-7\%) environmental concentrations of $\mathrm{CO}_{2}$ (Goetz et al, 2001; Gorman et al, 1984, 1988), and i.v. infusions of isoproterenol (nonspecific beta adrenergic receptor agonist with limited brain penetration (Balon et al, 1988)) or cholecystokinin (CCK (Bradwejn et al, 1991)) can elicit panic attacks in many patients with panic disorder compared with healthy controls. Furthermore, arousal-related drugs such as yohimbine (a non-selective alpha 2 adrenergic receptor antagonist) also provoke panic attacks in many panic disorder patients (Cowley et al, 1991; Liebowitz et al, 1986a, b) and in our animal model of panic (Shekhar et al, 2006). Reduced central inhibitory GABAergic activity has been reported in subjects with panic disorder (Goddard et al, 2001), which may lead to disruption of arousal-related neural pathways to induce panic vulnerability. The hypothalamus has long been implicated in generating a coordinated emotional and cardio-respiratory arousal (see the review by DiMicco et al, 2002), and in our panic model, chronically inhibiting GABA synthesis in the $\mathrm{DMH} / \mathrm{PeF}$ produces similar vulnerability to NaLac challenges (Johnson and Shekhar, 2006; Johnson et al, 2008; Shekhar et al, 1996, 1997, 2000, 2006). Furthermore, the hypothalamus receives and responds to interoceptive sensory input (eg, vasomotor activity, hunger, thirst, altered $\mathrm{CO}_{2} / \mathrm{pH}$ ) to coordinate neural processes (autonomic, neuroendocrine, and behavioral) to maintain optimal physiological homeostasis. Thus, lack of GABAergic tone in the hypothalamus (as is observed in panic disorder patients and induced in our animal model of panic) could make an organism vulnerable to panic responses to subtle changes in interoceptive sensory input. Finally, the medial prefrontal cortex (which has been shown to be hyporesponsive in panic disorder patients during anticipatory anxiety (Boshuisen et al, 2002)) tonically inhibits the DMH/PeF region (Bard, 1928; Bard and Mountcastle, 1948), and cognitive behavioral therapy, 
which is an effective treatment for panic disorder (Barlow, 1997), may restore this cortical inhibition (see Figure 8 for hypothetical pathways).

In summary, $\mathrm{Na}+$ appears to be the critical sensory element in i.v. NaLac-induced panic responses in panicprone rats (ie, with disruption of GABAergic tone in the $\mathrm{DMH}$ ). Furthermore, application of NaLac, but not lactic acid or D-mannitol, induces a significant increase in the number of action potentials in neurons in the $\mathrm{A} 3 \mathrm{Vr}$ neurons that project to the $\mathrm{DMH}$, which suggest that local concentration-sensitive $\mathrm{Na}_{\mathrm{X}}$ channels might be responsible for this effect. We suggest that NaLac-induced increases in the firing of $\mathrm{A} 3 \mathrm{Vr}$ neurons can cause excitation of $\mathrm{DMH}$ neurons previously compromised, which relays this signal to forebrain limbic structures such as the bed nucleus of the stria terminalis to mediate anxiety responses, and specific brainstem sympathetic and parasympathetic pathways to mediate the respiratory and cardiovascular components of the panic-like response (Johnson et al, 2008) (see Figure 8 for hypothetical pathways), and this might be a putative mechanism for the provocation of panic attacks in subjects with panic disorder.

\section{ACKNOWLEDGEMENTS}

We are grateful to Donald G Rainnie, PhD, for his expert technical advice in electrophysiological studies.

\section{DISCLOSURE}

The authors declare that this work was supported by grants from NIH: MH52619 to AS. Over the last 3 years AS and PLJ received research grants from Johnson \& Johnson and Eli Lilly for conducting preclinical studies that are unrelated to this paper.

\section{REFERENCES}

Abshire VM, Hankins KD, Roehr KE, DiMicco JA (1988). Injection of L-allylglycine into the posterior hypothalamus in rats causes decreases in local GABA which correlate with increases in heart rate. Neuropharmacology 27: 1171-1177.

Bailey TW, Nicol GD, Schild JH, DiMicco JA (2003). Synaptic and membrane properties of neurons in the dorsomedial hypothalamus. Brain Res 985: 150-162.

Balon R, Pohl R, Yeragani VK, Rainey JM, Weinberg P (1988). Lactate- and isoproterenol-induced panic attacks in panic disorder patients and controls. Psychiatry Res 23: 153-160.

Bard P (1928). A diencephalic mechanism for the expression of rage with special reference to the sympathetic nervous system. Am J Physiol 84 : 490-515.

Bard P, Mountcastle VB (1948). Some forebrain mechanisms involved in the expression of rage with special reference to suppression of angry behavior. Res Publ Assoc Res Nerv Ment Dis 27: $362-404$

Barlow DH (1997). Cognitive-behavioral therapy for panic disorder: current status. J Clin Psychiatry 58(Suppl 2): 32-36; discussion 36-37.

Boshuisen ML, Ter Horst GJ, Paans AM, Reinders AA, den Boer JA (2002). rCBF differences between panic disorder patients and control subjects during anticipatory anxiety and rest. Biol Psychiatry 52: 126-135.
Bourque CW, Oliet SH, Richard D (1994). Osmoreceptors, osmoreception, and osmoregulation. Front Neuroendocrinol 15: 231-274.

Bradwejn J, Koszycki D, Shriqui C (1991). Enhanced sensitivity to cholecystokinin tetrapeptide in panic disorder. Clinical and behavioral findings. Arch Gen Psychiatry 48: 603-610.

Chamberlin NL, Saper CB (1994). Topographic organization of respiratory responses to glutamate microstimulation of the parabrachial nucleus in the rat. J Neurosci 14: 6500-6510.

Chen T, Hul R Dong YX, Li YQ, Mizuno N (2004). Endomorphin 1 - and endomorphin 2-like immunoreactive neurons in the hypothalamus send axons to the parabrachial nucleus in the rat. Neurosci Lett 357: 139-142.

Cowley DS, Dager SR, Roy-Byrne PP, Avery DH, Dunner DL (1991). Lactate vulnerability after alprazolam versus placebo treatment of panic disorder. Biol Psychiatry 30: 49-56.

De Novellis V, Stotz-Potter EH, Morin SM, Rossi F, DiMicco JA (1995). Hypothalamic sites mediating cardiovascular effects of microinjected bicuculline and EAAs in rats. Am J Physiol 269(1 Pt 2): R131-R140.

DiMicco J, Monroe AJ (1996). Stimulation of metabotropic glutamate receptors in the dorsomedial hypothalamus elevates heart rate in rats. Am J Physiol 270(5 Pt 2): R1115-R1121.

DiMicco JA, Samuels BC, Zaretskaia MV, Zaretsky DV (2002). The dorsomedial hypothalamus and the response to stress: part renaissance, part revolution. Pharmacol Biochem Behav 71: 469-480.

DSM-IV (1994). Diagnostic and Statistical Manual-4th edn $D S M-I V)$. American Psychiatric Association: Washington, DC.

Fernandez-Pascual S, Mukala-Nsengu-Tshibangu A, Martin Del Rio R, Tamarit-Rodriguez J (2004). Conversion into GABA (gamma-aminobutyric acid) may reduce the capacity of L-glutamine as an insulin secretagogue. Biochem J 379(Pt 3): 721-729.

File SE (1980). The use of social interaction as a method for detecting anxiolytic activity of chlordiazepoxide-like drugs. J Neurosci Methods 2: 219-238.

File SE, Seth P (2003). A review of 25 years of the social interaction test. Eur J Pharmacol 463: 35-53.

Fontes MA, Tagawa T, Polson JW, Cavanagh SJ, Dampney RA (2001). Descending pathways mediating cardiovascular response from dorsomedial hypothalamic nucleus. Am J Physiol Heart Circ Physiol 280: H2891-H2901.

George DT, Lindquist T, Nutt DJ, Ragan PW, Alim T, McFarlane V et al (1995). Effect of chloride or glucose on the incidence of lactate-induced panic attacks. Am J Psychiatry 152: 692-697.

Goddard AW, Mason GF, Almai A, Rothman DL, Behar KL, Petroff OA et al (2001). Reductions in occipital cortex GABA levels in panic disorder detected with 1h-magnetic resonance spectroscopy. Arch Gen Psychiatry 58: 556-561.

Goetz RR, Klein DF, Gorman JM (1994). Consistencies between recalled panic and lactate-induced panic. Anxiety 1: $31-36$.

Goetz RR, Klein DF, Papp LA, Martinez JM, Gorman JM (2001). Acute panic inventory symptoms during $\mathrm{CO}(2)$ inhalation and room-air hyperventilation among panic disorder patients and normal controls. Depress Anxiety 14: 123-136.

Goldstein DB (1966). D-amino acid oxidase in brain: distribution in several species and inhibition by pentobarbitone. J Neurochem 13: 1011-1016.

Gorman JM, Askanazi J, Liebowitz MR, Fyer AJ, Stein J, Kinney JM et al (1984). Response to hyperventilation in a group of patients with panic disorder. Am J Psychiatry 141: 857-861.

Gorman JM, Battista D, Goetz RR, Dillon DJ, Liebowitz MR, Fyer AJ et al (1989). A comparison of sodium bicarbonate and sodium lactate infusion in the induction of panic attacks. Arch Gen Psychiatry 46: 145-150. 
Gorman JM, Fyer MR, Goetz R, Askanazi J, Liebowitz MR, Fyer AJ et al (1988). Ventilatory physiology of patients with panic disorder. Arch Gen Psychiatry 45: 31-39.

Grob M, Drolet G, Mouginot D (2004). Specific Na+ sensors are functionally expressed in a neuronal population of the median preoptic nucleus of the rat. J Neurosci 24: 3974-3984.

Grob M, Trottier JF, Drolet G, Mouginot D (2003). Characterization of the neurochemical content of neuronal populations of the lamina terminalis activated by acute hydromineral challenge. Neuroscience 122: 247-257.

Hiyama TY, Watanabe E, Okado H, Noda M (2004). The subfornical organ is the primary locus of sodium-level sensing by $\mathrm{Na}(\mathrm{x})$ sodium channels for the control of salt-intake behavior. J Neurosci 24: 9276-9281.

Hochstenbach SL, Ciriello J (1996). Effect of Lesions of forebrain circumventricular organs on c-fos expression in the central nervous system to plasma hypernatrmia. Brain Res 713: 17-28.

Horton RW, Chapman AG, Meldrum BS (1978). Regional changes in cerebral GABA concentration and convulsions produced by D and by L-allylglycine. J Neurochem 30: 1501-1504.

Iyadomi M, Iyadomi I, Kumamoto E, Tomokuni K, Yoshimura M (2000). Presynaptic inhibition by baclofen of miniature EPSCs and IPSCs in substantia gelatinosa neurons of the adult rat spinal dorsal horn. Pain 85: 385-393.

Johnson PL, Shekhar A (2006). Panic-prone state induced in rats with GABA dysfunction in the dorsomedial hypothalamus is mediated by NMDA receptors. J Neurosci 26: 7093-7104.

Johnson PL, Truitt WA, Fitz SD, Lowry CA, Shekhar A (2008). Neural pathways underlying lactate-induced panic. Neuropsychopharmacology 33: 2093-2107.

Kobelt P, Paulitsch S, Goebel M, Stengel A, Schmidtmann M, van der Voort IR et al (2006). Peripheral injection of CCK-8S induces Fos expression in the dorsomedial hypothalamic nucleus in rats. Brain Res 1117: 109-117.

Kovacs KJ, Sawchenko PE (1993). Mediation of osmoregulatory influences on neuroendocrine corticotropin-releasing factor expression by the ventral lamina terminalis. Proc Natl Acad Sci USA 90: 7681-7685.

Lao LJ, Kumamoto E, Luo C, Furue H, Yoshimura M (2001). Adenosine inhibits excitatory transmission to substantia gelatinosa neurons of the adult rat spinal cord through the activation of presynaptic A(1) adenosine receptor. Pain 94: 315-324.

Liebowitz MR, Fyer AJ, Gorman JM, Campeas R, Levin A, Davies SR et al (1986a). Alprazolam in the treatment of panic disorders. J Clin Psychopharmacol 6: 13-20.

Liebowitz MR, Fyer AJ, Gorman JM, Dillon D, Appleby IL, Levy G et al (1984). Lactate provocation of panic attacks. I. Clinical and behavioral findings. Arch Gen Psychiatry 41: 764-770.

Liebowitz MR, Gorman JM, Fyer A, Dillon D, Levitt M, Klein DF (1986b). Possible mechanisms for lactate's induction of panic. Am J Psychiatry 143: 495-502.

Magee WJ, Eaton WW, Wittchen HU, McGonagle KA, Kessler RC (1996). Agoraphobia, simple phobia, and social phobia in the National Comorbidity Survey. Arch Gen Psychiatry 53: 159-168.

Neims AH, Zieverink WD, Smilack JD (1966). Distribution of D-amino acid oxidase in bovine and human nervous tissues. J Neurochem 13: 163-168.

Oliet SH, Bourque CW (1993). Mechanosensitive channels transduce osmosensitivity in supraoptic neurons. Nature 364: 341-343.

Orlowski M, Reingold DF, Stanley ME (1977). D-and L-stereoisomers of allylglycine: convulsive action and inhibition of brain L-glutamate decarboxylase. J Neurochem 28: 349-353.

Paxinos G, Watson C (2005). The Rat Brain in Stereotaxic Coordinates 5th edn. Elsevier Academic Press: New York.

Pellegrino LJ, Pellegrino AS, Cushman AJ (1979). A Stereotaxic Atlas of the Rat Brain 2nd edn. Plenum Press: New York.

Peskind ER, Jensen CF, Pascualy M, Tsuang D, Cowley D, Martin DC et al (1998). Sodium lactate and hypertonic sodium chloride induce equivalent panic incidence, panic symptoms, and hypernatremia in panic disorder. Biol Psychiatry 44: $1007-1016$.

Rall W (1969). Time constants and electrotonic length of membrane cylinders and neurons. Biophysical Journal 9: 1483-1508.

Reingold DF, Orlowski M (1978). Inhibition of human and mouse brain glutamate decarboxylase by the alpha-keto analogs of cysteine and homocysteine. Biochem Pharmacol 27: 2567-2570.

Reingold DF, Orlowski M (1979). Inhibition of brain glutamate decarboxylase by 2-keto-4-pentenoic acid, a metabolite of allylglycine. J Neurochem 32: 907-913.

Richard D, Bourque CW (1992). Synaptic activation of rat supraoptic neurons by osmotic stimulation of the organum vasculosum lamina terminalis. Neuroendocrinology 55: 609-611.

Samuels BC, Zaretsky DV, DiMicco JA (2004). Dorsomedial hypothalamic sites where disinhibition evokes tachycardia correlate with location of raphe-projecting neurons. Am J Physiol Regul Integr Comp Physiol 287: R472-R478.

Schruers K, van Diest R, Overbeek T, Griez E (2002). Acute L-5hydroxytryptophan administration inhibits carbon dioxideinduced panic in panic disorder patients. Psychiatry Res 113: 237-243.

Seroogy KB, Herman JP (1996). In situ hybridization approaches to the study of the nervous system. In: Turner AJ, Bachelard HS (eds). Neurochemistry-A Practical Approach 2nd edn. Oxford University Press: New York. pp 121-150.

Shekhar A, DiMicco JA (1987). Defense reaction elicited by injection of GABA antagonists and synthesis inhibitors into the posterior hypothalamus in rats. Neuropharmacology 26: 407-417.

Shekhar A, Hingtgen JN, DiMicco JA (1990). GABA receptors in the posterior hypothalamus regulate experimental anxiety in rats. Brain Res 512: 81-88.

Shekhar A, Johnson PL, Sajdyk TJ, Fitz SD, Keim SR, Kelley PE et al (2006). Angiotensin-II is a putative neurotransmitter in lactate-induced panic-like responses in rats with disruption of GABAergic inhibition in the dorsomedial hypothalamus. J Neurosci 26: 9205-9215.

Shekhar A, Katner JS (1995). Dorsomedial hypothalamic GABA regulates anxiety in the social interaction test. Pharmacol Biochem Behav 50: 253-258.

Shekhar A, Keim SR (1997). The circumventricular organs form a potential neural pathway for lactate sensitivity: implications for panic disorder. J Neurosci 17: 9726-9735.

Shekhar A, Keim SR (2000). LY354740, a potent group II metabotropic glutamate receptor agonist prevents lactateinduced panic-like response in panic-prone rats. Neuropharmacology 39: 1139-1146.

Shekhar A, Keim SR, Simon JR, McBride WJ (1996). Dorsomedial hypothalamic GABA dysfunction produces physiological arousal following sodium lactate infusions. Pharmacol Biochem Behav 55: 249-256.

Shekhar A, Sajdyk TJ, Gehlert DR, Rainnie DG (2003). The amygdala, panic disorder, and cardiovascular responses. Ann NY Acad Sci 985: 308-325.

Shekhar A, Sims LS, Bowsher RR (1993). GABA receptors in the region of the dorsomedial hypothalamus of rats regulate anxiety in the elevated plus-maze test II. Physiological measures. Brain Res 627: 17-24.

Singewald N, Salchner P, Sharp T (2003). Induction of c-Fos expression in specific areas of the fear circuitry in rat forebrain by anxiogenic drugs. Biol Psychiatry 53: 275-283.

Soltis RP, DiMicco JA (1991). Interaction of hypothalamic GABAA and excitatory amino acid receptors controlling heart rate in rats. Am J Physiol 261(2 Pt 2): R427-R433.

Soltis RP, DiMicco JA (1992). Hypothalamic excitatory amino acid receptors mediate stress-induced tachycardia in rats. $\mathrm{Am}$ J Physiol 262(4 Pt 2): R689-R697. 
Thompson RH, Swanson LW (1998). Organization of inputs to the dorsomedial nucleus of the hypothalamus: a reexamination with Fluorogold and PHAL in the rat. Brain ResBrain ResRev 27: 89-118.

Vickers K, McNally RJ (2005). Respiratory symptoms and panic in the National Comorbidity Survey: a test of Klein's suffocation false alarm theory. Behav Res Ther 43: 1011-1018.

Watanabe E, Fujikawa A, Matsunaga H, Yasoshima Y, Sako N, Yamamoto $\mathrm{T}$ et al (2000). Nav2/NaG channel is involved in control of salt-intake behavior in the CNS. J Neurosci 20: 7743-7751.
Williams RH, Jensen LT, Verkhratsky A, Fugger L, Burdakov D (2007). Control of hypothalamic orexin neurons by acid and CO2. Proc Natl Acad Sci USA 104: 10685-10690.

Yoshimura M, Nishi S (1995). Primary afferent-evoked glycineand GABA-mediated IPSPs in substantia gelatinosa neurones in the rat spinal cord in vitro. J Physiol 482(Pt 1): 29-38.

Ziegler DR, Cullinan WE, Herman JP (2005). Organization and regulation of paraventricular nucleus glutamate signaling systems: N-methyl-D-aspartate receptors. J Comp Neurol 484: 43-56. 